\title{
A concept for a satellite mission to measure cloud ice water path, ice particle size, and cloud altitude ${ }^{\dagger}$
}

\author{
S. A. Buehler, ${ }^{a *}$ C. Jiménez, ${ }^{a}$ K. F. Evans, ${ }^{b}$ P. Eriksson, ${ }^{c}$ B. Rydberg, ${ }^{c}$ A. J. Heymsfield, ${ }^{d}$ \\ C. J. Stubenrauch, ${ }^{\mathrm{e}}$ U. Lohmann, ${ }^{\mathrm{f}}$ C. Emde, ${ }^{\mathrm{g}}$ V. O. John, ${ }^{\mathrm{h}}$ T. R. Sreerekha ${ }^{\mathrm{i}}$ and C. P. Davis ${ }^{\mathrm{j}}$ \\ ${ }^{a}$ Luleå Technical University, Department of Space Science, Kiruna, Sweden \\ ${ }^{\mathrm{b}}$ Department of Atmospheric and Oceanic Sciences, University of Colorado, USA \\ c Department of Radio and Space Science, Chalmers University of Technology, Gothenburg, Sweden \\ d NCAR, Boulder, Colorado, USA \\ e CNRS/IPSL - Laboratoire de Meteorologie Dynamique, Ecole Polytechnique, Palaiseau, France \\ ${ }^{\mathrm{f}}$ ETH Zurich, Institute for Atmospheric and Climate Science, Switzerland \\ g Deutsches Zentrum für Luft- und Raumfahrt, Institut für Physik der Atmosphäre, Oberpfaffenhofen, Germany \\ ${ }^{\mathrm{h}}$ Rosenstiel School of Marine and Atmospheric Science, University of Miami, USA \\ i Met Office, Exeter, UK \\ j School of Geosciences, University of Edinburgh, UK
}

\begin{abstract}
A passive satellite radiometer operating at submillimetre wavelengths can measure cloud ice water path (IWP), ice particle size, and cloud altitude. The paper first discusses the scientific background for such measurements. Formal scientific mission requirements are derived, based on this background and earlier assessments. The paper then presents a comprehensive prototype instrument and mission concept, and demonstrates that it meets the requirements. The instrument is a conically scanning 12-channel radiometer with channels between 183 and $664 \mathrm{GHz}$, proposed to fly in tandem with one of the Metop satellites. It can measure IWP with a relative accuracy of approximately $20 \%$ and a detection threshold of approximately $2 \mathrm{~g} \mathrm{~m}^{-2}$. The median mass equivalent sphere diameter of the ice particles can be measured with an accuracy of approximately $30 \mu \mathrm{m}$, and the median IWP cloud altitude can be measured with an accuracy of approximately $300 \mathrm{~m}$. All the above accuracies are median absolute error values; root mean square error values are approximately twice as high, due to rare outliers. Copyright (c) 2007 Royal Meteorological Society
\end{abstract}

KEY WORDS submillimetre waves; CIWSIR; mission requirements

Received 15 March 2007; Revised 16 July 2007; Accepted 25 July 2007

\section{Introduction}

The use of passive submillimetre-wave measurements to retrieve cloud ice water content and ice particle size was suggested 12 years ago by Evans and Stephens (1995), and refined in subsequent publications (e.g. Evans et al., 1998). Since then, scientists have submitted several mission proposals that focus on this technique to US and European space agencies (Kunzi, 2001; Ackermann et al., 2005, 2006; Buehler, 2005). The purpose of this article is to present and explain the latest proposal to the European Space Agency (ESA; Buehler, 2005), which was made for the 2005 Earth Explorer call. The proposal was called 'Cloud ice water path submillimetre imaging radiometer' (CIWSIR). The mission was not selected directly for a pre-phase-A study, but there was a strong recommendation to continue preparatory activities,

\footnotetext{
* Correspondence to: S. A. Buehler, Luleå Technical University, Department of Space Science, Box 812, 98128 Kiruna, Sweden.

E-mail: sbuehler@irv.se

${ }^{\dagger}$ The contribution of T. R. Sreerekha of the Met Office, Exeter, was prepared as part of an official duty as an employee of the UK Government. It is published with the permission of the Controller of HER Majesty's Stationery Office and the Queen's Printer for Scotland.
}

including the collection of more data with aircraft prototypes.

The paper draws not only on the work performed for the mission proposal, but also on the work performed within a subsequent ESA study (Jarret et al., 2007). More details on the retrieval simulations that were performed in that study can be found in Jiménez et al. (2007).

The structure of the paper is as follows: section 2 presents the scientific background and the specific objectives for a submillimetre-wave cloud mission. Section 3 deals with the derivation of formal scientific mission requirements. Section 4 presents the prototype instrument and mission concept, and demonstrates that it meets the requirements. Finally, section 5 presents a summary and some conclusions.

\section{Background and objectives}

\subsection{Ice clouds}

\subsubsection{Ice clouds in the climate system}

Cloud ice and water vapour are the two components of the hydrological cycle in the upper troposphere, and both 
are currently poorly measured. The hydrological cycle is the most important subsystem of the climate system for life on the planet, hence its understanding is an important scientific goal. Great progress has already been made towards this goal, except in the upper troposphere, where our knowledge is still very limited.

Ice clouds play an important role in the energy budget of the atmosphere. They are at high altitudes, absorb long-wave radiation from below and, as they are cold, emit little infrared (IR) radiation. This greenhouse effect warms the Earth-atmosphere system. On the other hand, cirrus clouds reflect incoming solar short-wave (SW) radiation and hence cool the Earth-atmosphere system. The net effect is crucial for the atmosphere, but will depend highly on the cloud's horizontal extent, vertical position, ice water content, and ice particle microphysical properties, which all influence the cloud's optical thickness. Thus, the special properties of cirrus clouds have a strong impact on radiative exchanges. Furthermore, cirrus clouds affect the atmospheric energy budget by releasing latent heat during the depositional growth of ice particles and by absorbing heat upon their sublimation. Eventually ice particles, if large enough, settle through the atmosphere and may enhance precipitation generation in lower clouds by the seeder-feeder mechanism (e.g. Houze, 1994).

The importance of clouds in weather and climate processes has been recognized through a number of observational and modelling studies and is emphasized in the third Report of the Intergovernmental Panel on Climate Change (IPCC; Stocker et al., 2001).

\subsubsection{Representation of ice clouds in climate models}

All general circulation models (GCMs) for weather prediction and climate simulation now include the vertical distribution of condensate (Doms and Schaettler, 1999; Roeckner et al., 2003). Most models contain the liquid and ice water content (LWC and IWC) as prognostic variables, and forecast their value at each model time step and grid point from separate water mass continuity equations (e.g. Lohmann and Roeckner, 1996). However, the models contain considerable uncertainties and oversimplifications, largely introduced by the assumptions on ice sedimentation velocities and by the treatment of advection from one time step to the next. Thus, recent sensitivity studies, like the ones by Wilson (2000) and Reinhardt and Wacker (2004), find that LWC and IWC vary considerably depending on the assumptions made.

The vertically integrated IWC is called ice water path (IWP). The climatologies of IWP in different climate models have considerable discrepancies. John and Soden (2006) show a comparison of the climatologies for zonal annual mean IWP for the models in the IPCC AR4 model data archive. They vary by up to an order of magnitude between the different models. As the paper shows, the discrepancies in the model-predicted IWP response to a $\mathrm{CO}_{2}$ doubling are even more striking. Even the sign of the response is uncertain. Some models predict an increase of cloud ice at latitudes where others predict a decrease.
These discrepancies in IWP arise because the different models make different assumptions on ice particle properties and on the thresholds used to convert cloud ice to precipitation. Most important in this respect are assumptions on ice particle size, mass, and cross-sectional area, because these properties directly influence the particle fall velocities (Heymsfield and Iaquinta, 2000; Kristjansson et al., 2000).

The effective size can be defined in different ways, depending on application. For example, researchers working with IR radiative transfer often define it as the mean diameter, weighted by the particle cross-section, $D_{\text {eff }}$. We prefer a definition that is closely related to the particle mass, either the ice water content weighted equivalent mass diameter, $D_{\text {mean }}$, or the median mass equivalent sphere diameter, $D_{\text {me }}$. Values of $D_{\text {mean }}$ and $D_{\text {me }}$ are numerically very close, but the value of $D_{\text {eff }}$ differs significantly from the other two. It is approximately $10-50 \%$ lower (Heymsfield, 2003).

\subsection{Measurements}

\subsubsection{In situ measurements}

In situ measurements with aircraft-borne sensors provide the most detailed information on ice clouds. Good summaries of recent measurement campaigns are given in Lynch et al. (2002), and more recently in Heymsfield et al. (2004), Stubenrauch et al. (2004a), and Gayet et al. (2004). From these campaigns, we know the typical sizes and shapes of ice particles in clouds. We have also learned that ice particles tend to be larger at higher temperatures and higher IWC, and tend to be smaller for low temperature and IWC. However, the natural variability is very large and therefore parametrizations of the particle size distribution as a function of temperature and IWC can only be rough approximations.

The validation of GCMs requires global data with long time coverage. For economical and practical reasons, this can not be achieved with in situ measurements.

\subsubsection{Satellite measurements}

Satellite-borne remote-sensing instruments can provide frequent global measurements of the atmosphere on a long-term basis. The existing instruments operate in different parts of the electromagnetic spectrum and use a number of techniques to detect and measure ice clouds.

IR sensors like the High-Resolution and Advanced Infrared Sounders (HIRS and AIRS) measure thermal emission from clouds, atmosphere, and surface. Opaque ice clouds are radiatively colder than the surface, because they are at high altitudes where the ambient temperature is low. Cirrus clouds with visible optical thickness between 0.7 and 3.8 are called semi-transparent (Stubenrauch et al., 2004a). For these clouds the IR brightness temperatures are higher than the ambient temperature. Cirrus IR emissivities at different wavelengths allow us to retrieve IWP and $D_{\text {eff }}$ for such semitransparent cirrus clouds (Rädel et al., 2003; Stubenrauch et al., 2004b). 
Such clouds constitute approximately half of all high clouds. On average they have an IWP of $30 \mathrm{~g} \mathrm{~m}^{-2}$ and a $D_{\text {eff }}$ of $55 \mu \mathrm{m}$. For thicker cirrus clouds, the method is not applicable, because they act like black bodies and the sensor sees only the emission from the cloud top.

Sensors in the visible (VIS) spectral range, such as the POLarization and Directionality of the Earth's Reflectances (POLDER) radiometer, see the sunlight reflected by the clouds. The polarized reflectivity depends strongly on ice particle size and shape, therefore such measurements can be used for a retrieval of $D_{\mathrm{me}}$ and for a rough crystal habit classification. The measurement only works if the surface albedo is not too high. Furthermore, for thick clouds the measurement is limited to particles near the cloud top. Instruments like second Along-Track Scanning Radiometer (ATSR-2) that have both VIS and IR channels can use emitted and reflected radiation simultaneously.

Microwave sensors, such as the Advanced Microwave Sounding Unit (AMSU-B) and Special Sensor Microwave/Temperature (SSM-T2), detect the cloud transmission, seeing through even thick ice clouds. The principle of this measurement is explained in detail in section 2.3. The currently operational microwave sensors are sensitive only to relatively thick ice clouds (e.g. Hong et al., 2005), because the interaction of millimetre-wave radiation with cloud ice particles is not very strong. For submillimetrewave radiation, the interaction is significantly stronger.

The potential of millimetre and submillimetre satellite observations for cloud ice retrieval has been demonstrated with data from the limb-sounding instruments Odin-SMR (submillimetre receiver; Eriksson et al., 2007) and Aura MLS (microwave limb sounder; Li et al., 2005). The high incidence angles of these instruments limit the altitude coverage, which starts around $11 \mathrm{~km}$ for SMR $(500 \mathrm{GHz})$ and around $6 \mathrm{~km}$ for MLS (230 GHz). The geographical coverage is restricted to the orbit plane, where each footprint corresponds to a horizontal area with a width of a few kilometres and a length exceeding $100 \mathrm{~km}$. This makes individual ice cloud retrievals from these limbsounding instruments inaccurate when viewing clouds with small horizontal extent, such as convective anvils.

Since April 2006, the American CLOUDSAT mission (Stephens et al., 2002) has been flying a cloud profiling radar (CPR) at $95 \mathrm{GHz}$ with high vertical resolution. Radar-only methods at $95 \mathrm{GHz}$ have a dynamic range in IWP from approximately $5 \mathrm{~g} \mathrm{~m}^{-2}$ to several $1000 \mathrm{~g} \mathrm{~m}^{-2}$ (G. Stephens, personal communication). However, $95 \mathrm{GHz}$ radar data alone do not give very accurate estimates of IWC and IWP, since the radar reflectivity depends on the particle size distribution, which varies from cloud to cloud (Atlas et al., 1995). This shortcoming can be mitigated by using simultaneous optical depth estimates from the Imaging Infrared Radiometer (IIR) or Moderate-Resolution Imaging Spectroradiometer (MODIS) instrument or lidar-derived extinction from the Cloud-Aerosol Lidar with Orthogonal Polarization (CALIOP) instrument to constrain the particle size distribution. (IIR and CALIOP are part of the
Cloud-Aerosol Lidar and Infrared Pathfinder Satellite Observations (CALIPSO) mission (Winker et al., 2003), which is flying in formation with CLOUDSAT and the other A-train satellites. MODIS is part of the Aqua mission, which is also on the A-train.) A recent study by Heymsfield et al. (2007) investigated the performance of a large set of radar, radar-optical depth, and combined radar/lidar IWC and IWP retrieval algorithms, using in situ aircraft data from Lagrangian spiral descents and simulated measurements. Their conclusion is that the radar/optical depth and radar/lidar combination can retrieve IWP with an accuracy of better than $20 \%$, for cloud cases where both radar and lidar provide information (approximately in the IWP range from 20 to $100 \mathrm{~g} \mathrm{~m}^{-2}$ ). For higher IWP, the errors were found to be larger because radar alone or radar/optical depth methods are less accurate and because of uncertainty in nonRayleigh scattering effects.

The planned ESA mission EarthCARE will also use a radar and a lidar, combined with two passive sensors.

\subsection{Basic mission idea}

\subsubsection{Science objectives}

To improve climate prediction, it is necessary to validate the IWC fields of GCMs and resolve the discrepancies. For this purpose, direct global measurements of IWC or its vertical integral IWP are required, at a resolution compatible with the GCMs and fine enough to resolve typical cirrus features. Global measurements of effective particle size $D_{\mathrm{me}}$ are needed to constrain the GCMs' assumptions on ice particle size, and hence ice particle fall velocity.

\subsubsection{Observation method}

A schematic picture of the observation geometry is shown in Figure 1. Since water vapour absorption is strong in the submillimetre-wave spectral range, the lower atmosphere is in most cases opaque. This has the desired effect that the surface and low clouds do not contribute to the upwelling radiation. Furthermore, in this frequency range the interaction between cirrus clouds and radiation is mainly by scattering, so emission and therefore cloud temperature are not important. The situation can be described to a good approximation as that of a layer of cloud ice lying on top of a radiation source. Hence, the effect of the cloud is to reduce the brightness temperature compared to the clear-sky case. The brightness temperature depression is proportional to the IWP, except for saturation effects that occur for high IWP at high frequencies. This linearity has the advantage that radiation averages correspond to the radiation of an average atmospheric state, i.e. problems related to beam-filling in the presence of inhomogeneities are less significant than for optical and IR techniques.

Figure 2 gives an example how thick ice clouds are seen at microwave frequencies by the AMSU-B instrument. Figure 2(a) and (b) show some AMSU data at 
(a)

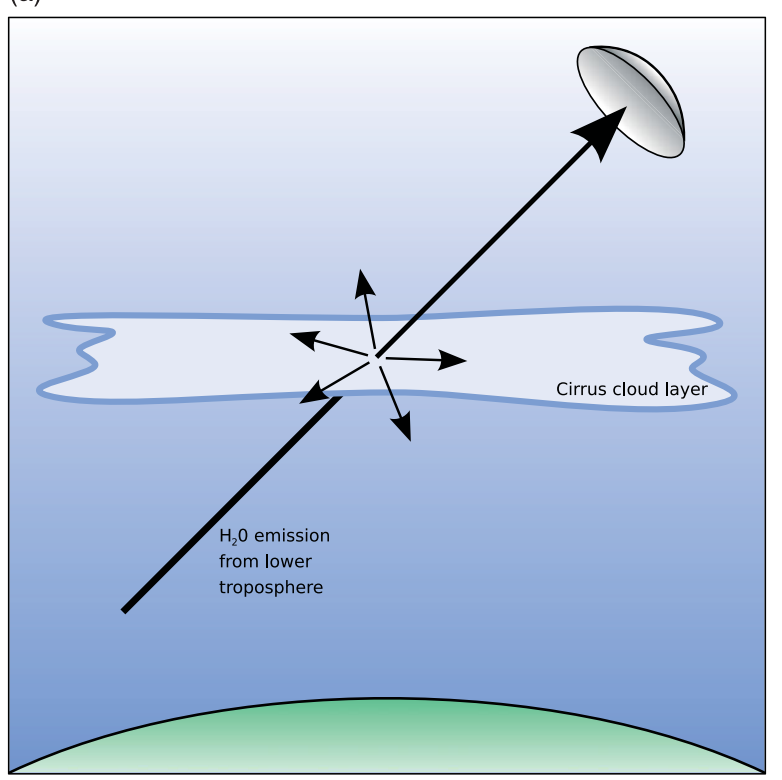

(b)

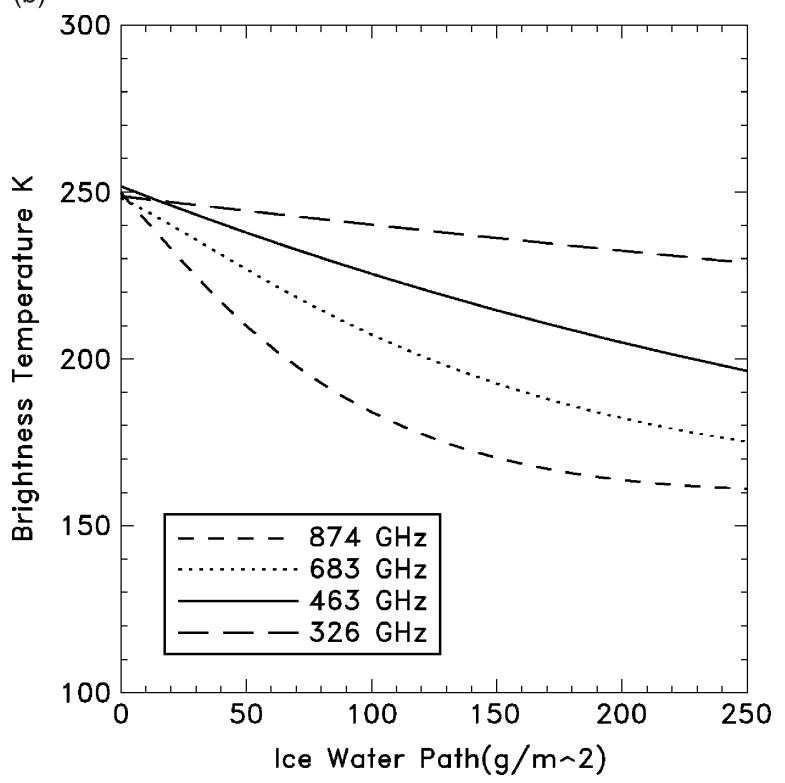

Figure 1. (a) The observation geometry. Some of the upwelling radiation is scattered away by the ice cloud. (b) Sensitivity of radiance to IWP for some different frequencies in the submillimetre-wave spectral range. Conditions: midlatitude winter, nadir viewing direction, homogeneous cloud between 5 and $7 \mathrm{~km}$ altitude, spherical ice particles of $200 \mu \mathrm{m}$ diameter. The simulation used a discrete ordinate iterative solution method (Emde et al., 2004) that is part of the open source Atmospheric Radiative Transfer Simulator ARTS (Buehler et al., 2005). This figure is available in colour online at www.interscience.wiley.com/qj

$183 \pm 7 \mathrm{GHz}$, and a model IWP field for comparison. Figure 2(c) and (d) show simulated radiances for the same AMSU channel and for a channel at $664 \mathrm{GHz}$. The figure demonstrates that radiative transfer simulations in the presence of ice clouds agree well with the available observations at AMSU frequencies and that the cloud signal is more pronounced at higher frequencies. (More details on the radiative signature of cloud ice can be found in Rydberg et al. (2007)). At the high-frequency end, the usable frequency range is limited by the rising opacity due to water vapour absorption, which will hide the ice clouds from the satellite sensor at frequencies above roughly $1 \mathrm{THz}$. The submillimetre frequency range thus presents a unique window for the observation of ice clouds.

The interaction of ice particles with radiation depends strongly on the ratio of particle size and wavelength. Figure 3 shows the sensitivity to particles of different sizes for some selected submillimetre channels. For comparison, the sensitivity for IR measurements and for radar backscatter at $95 \mathrm{GHz}$ (CLOUDSAT and EarthCARE CPR) are also shown. As demonstrated by the figure, measurements at different frequencies can be used to quantify the particle size distribution. To make accurate measurements of IWC or IWP, it is important that a significant part of the size distribution is detected. (Significant here means a part that contains a significant fraction of the total mass of ice.) Parts of the size distribution that are not detected will lead to errors in IWC, because the mass of ice hidden in particles of that size must be estimated from assumptions on the size distribution. This is the reason why neither IR measurements (seeing only very small particles), nor radar measurements (seeing only very large particles) can provide very accurate estimates of IWC. Millimetre/submillimetre measurements, combined with IR measurements for the very small ice particles, can provide a reasonable coverage of the size distribution.

\section{Scientific requirements}

As explained in section 2, uncertainties in the treatment of ice clouds in climate models are one of the main sources of uncertainty in climate predictions (Stephens et al., 1990). Progress is difficult, as long as there are no global data on ice water content and ice particle effective size for all types of clouds. The purpose of this section is to define the requirements for such data. Requirements for numerical weather prediction (NWP), although not the main goal of the proposed mission, are also considered.

\subsection{History}

Scientific requirements for submillimetre-wave satellite observations were examined in the context of three recent ESA studies (Charlton et al., 2002; Golding and Atkinson, 2002; Sreerekha et al., 2006). In all three cases, the task was carried out by scientists of the UK Met Office. The focus was not exclusively on cloud parameters, but on all meteorological parameters for which submillimetre observations could potentially add useful information. The emphasis was on operational meteorology, but requirements for climatological applications were also discussed. We will follow here to some extent the approach of these earlier studies, but will put the focus more strictly on cloud parameters. Results will be quoted mostly from the latest of these studies, which we 

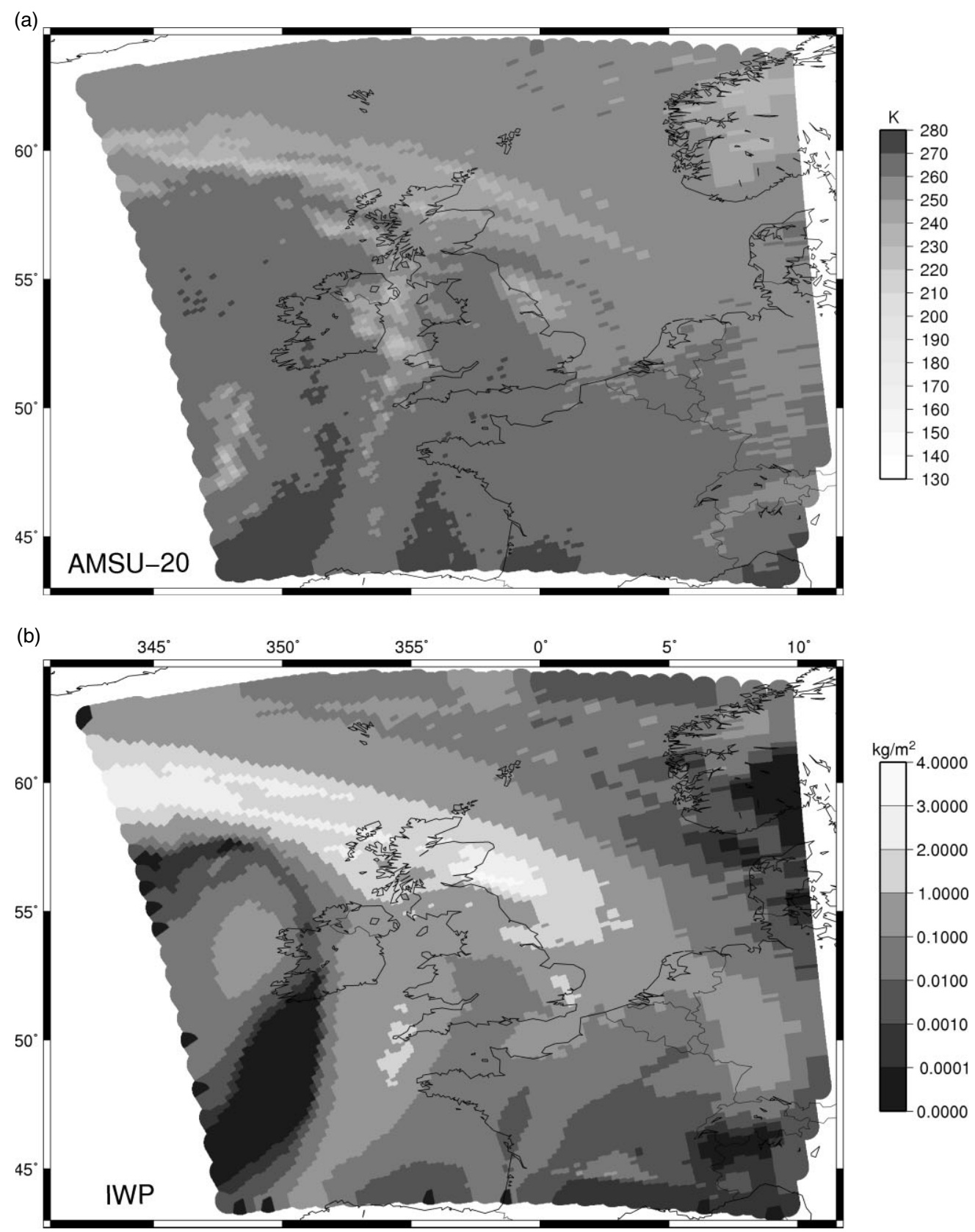

Figure 2. (a) AMSU Channel 20 measurements at $183.31 \pm 7 \mathrm{GHz}$ over the UK and northern parts of continental Europe, on 25 January 2002. The bright areas show the signature of the thick ice cloud associated with a frontal system passing over the UK. (b) Ice Water Path (IWP) from the Met Office (UK) mesoscale model. (c) Simulated AMSU measurement, based on the mesoscale model atmosphere. (d) Simulated measurement at $664 \mathrm{GHz}$. The simulations were done with the radiative transfer model ARTS, assuming a McFarquhar and Heymsfield (1997) size distribution for the ice particles. This parametrization was chosen for convenience, and because it is the parametrization used for operational EOS-MLS retrievals (Wu et al., 2006). The simulation for AMSU used the correct AMSU viewing angles, and the one for $664 \mathrm{GHz}$ a fixed viewing angle of $45^{\circ}$. Note the much stronger sensitivity to ice for the higher frequency.

will refer to as the ESA_RT study. It incorporates the results of the two earlier studies.

\subsection{Definitions and methodology}

Following Sreerekha et al. (2006), a scientific requirement is independent of technology and costs. It is a statement of the range of meteorological fields required for each different application and the resolution, accuracy and timeliness required. The scientific requirement will be different for every different application. This definition of scientific requirement also means that it is independent of the costs and independent of the availability of other observations. It is an absolute statement of requirement. The process of defining system requirements from a scientific requirement must take account of many things but most importantly the maximum cost-benefit and the availability of other observations.

For each application, there is usually no abrupt transition in the utility of an observation as its quality changes; improved observations (in terms of resolution, frequency, accuracy, etc.) are usually more useful while degraded 

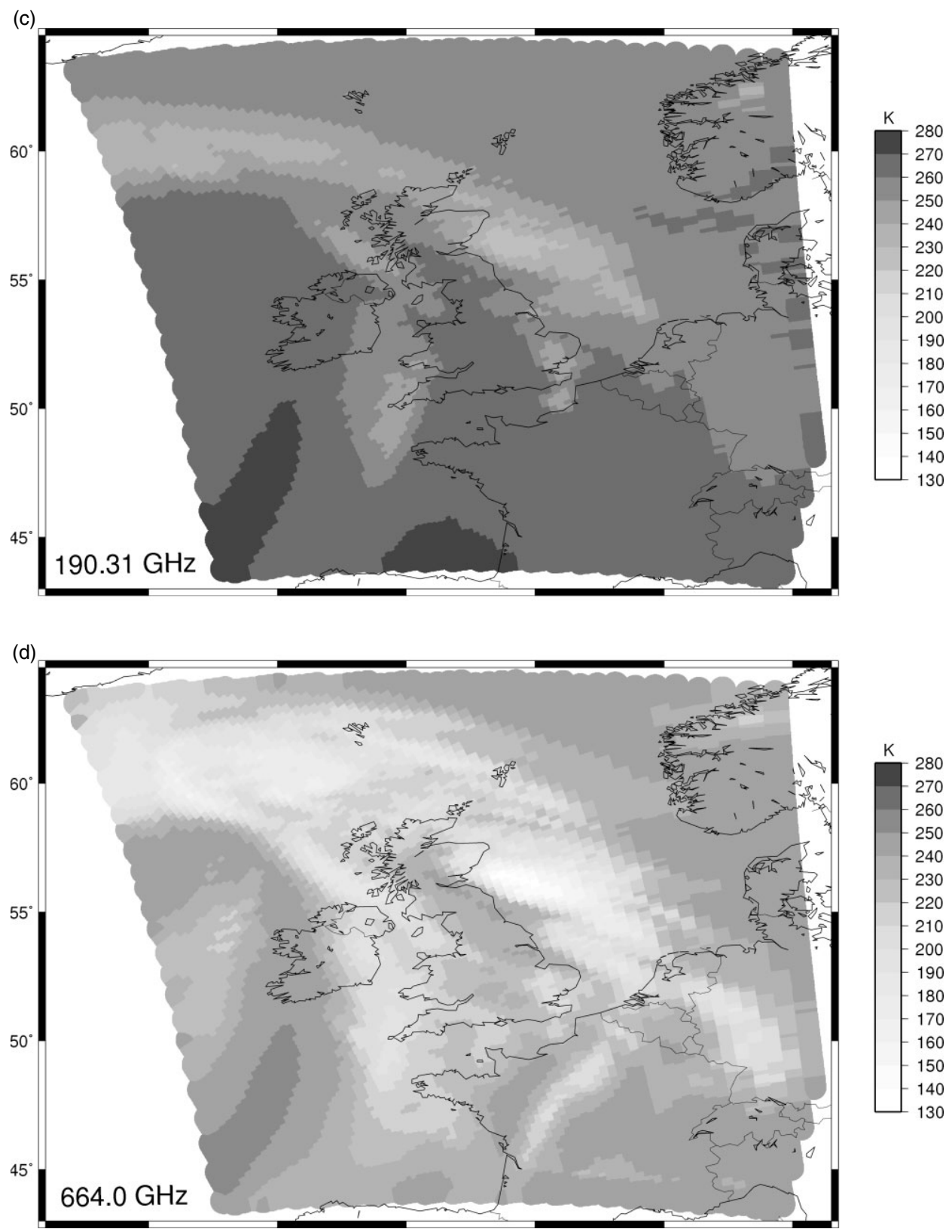

Figure 2. (Continued).

observations, although less useful, are rarely useless. Moreover, the range of utility varies from one application to another. The requirements for each parameter are expressed in terms of two values, an upper boundary 'maximum', 'target', or 'objective', and a lower boundary 'minimum' or 'threshold' requirement. The 'maximum' requirement is the value which, if exceeded, does not yield significant additional benefits. Maximum requirements are likely to evolve; as applications progress, they develop a capacity to make use of better observations. The 'minimum' requirement is the value below which the observation does not yield any significant benefit for the application in question. However, as a system that meets only minimum requirements is unlikely to be cost-effective, it should in most cases not be used as a minimum target level (for an acceptable system).
Within the range between the minimum and maximum requirements, the observations become progressively more useful. The ' $\max / \mathrm{min}$ ' method necessarily oversimplifies many aspects of the problems of stating scientific requirements; however, it has been adopted by the WMO as a simple and workable approach for achieving high-level statements of requirements.

Note that the terminology for the definition of scientific requirements in different assessments is generally not consistent. What we called 'scientific requirement' here is called 'user requirement' in Sreerekha et al. (2006). In the CIWSIR mission proposal (Buehler, 2005), the same concept is called 'observational requirement'; in the requirement database of the Committee on Earth Observation Satellites (CEOS) of the World Meteorological Organization (WMO), it is called 'observational user requirement' (Hinsman, 2003). 

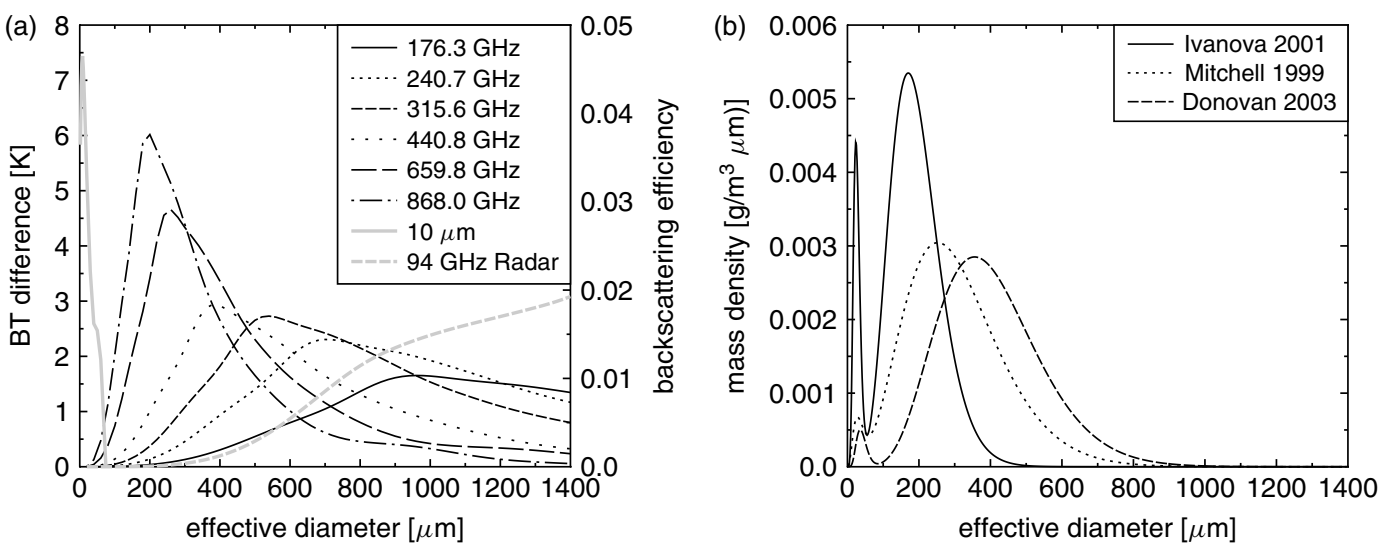

Figure 3. (a) The sensitivity of measurements at different frequencies to particle size. To generate this figure, a fixed amount of cloud ice (IWP $=0.001 \mathrm{~g} \mathrm{~m}^{-2}$ ) was put into narrow size distributions with different $D_{\text {eff }}$. For each $D_{\text {eff }}$, the difference between clear-sky and cloudy radiance is displayed. For comparison, the two grey curves show the size sensitivity for IR radiances at $10 \mu \mathrm{m}$ (solid), and for radar backscatter measurements at $95 \mathrm{GHz}$ (dashed). The right axis is for the radar curve, the left axis for all other curves. (b) Three typical ice particle size distributions from the literature (mass per size bin), all normalized to a total IWC of $0.5 \mathrm{~g} \mathrm{~m}^{-3}$.

\section{3. $\mathrm{CEOS} / \mathrm{WMO}$ requirement database}

The CEOS of WMO maintains a database of requirements for satellite observations of meteorological parameters (Hinsman, 2002, 2003). We will refer to this as the WMO/CEOS database.

Table I shows those elements from the WMO/CEOS database that are relevant for quantitative observations of cloud ice. The applications considered are: aviation meteorology, regional NWP, global NWP, and the Global Energy and Water Cycle Experiment (GEWEX), as an example of a climate application. The database contains only requirements for ice mass, and no requirements for ice particle size $D_{\mathrm{me}}$. Even the requirements for ice mass in this database have some problems, which have been addressed in the ESA_RT study and will be discussed in section 3.4. Here, we just quote the CEOS requirements as a starting point, without discussing them in detail.

Horizontal resolution requirements for IWC and IWP measurements are similar. The minimum requirement is between 100 and $250 \mathrm{~km}$, depending on application. The maximum requirement is between 10 and $50 \mathrm{~km}$. For the vertical resolution, the minimum requirement is $10 \mathrm{~km}$ for global NWP, $5 \mathrm{~km}$ for most climate applications, but below $1 \mathrm{~km}$ for aviation meteorology. The maximum vertical resolution requirements range from 1 to $0.15 \mathrm{~km}$, depending on application.

The accuracy minimum requirement is quoted as $20-25 \%$ for IWC, but as an absolute amount of $20 \mathrm{~g} \mathrm{~m}^{-2}$ for IWP. Note that $20 \mathrm{~g} \mathrm{~m}^{-2}$ corresponds to $20 \%$ for an IWP value of $100 \mathrm{~g} \mathrm{~m}^{-2}$, the value of a moderate cirrus cloud. (The role of absolute and relative requirements will be discussed further in section 3.7.) The maximum requirement for accuracy is $5-10 \%$ for IWC and $10 \mathrm{~g} \mathrm{~m}^{-2}$ for IWP.

The observation cycle minimum requirement is $12 \mathrm{~h}$, except for aviation meteorology, where it is $3 \mathrm{~h}$. The observation cycle maximum requirement is $3 \mathrm{~h}$ for climate applications, and between 1 and $0.5 \mathrm{~h}$ for NWP. Concerning delay requirements, the database confirms that climate applications can accept delays of a month and more. For NWP the minimum requirement is $2-4 \mathrm{~h}$, and the maximum requirement is $0.5-1 \mathrm{~h}$, depending on application.

\subsection{ESA_RT study findings}

This section briefly summarizes the findings of the study that was carried out by the Met Office, UK, in the framework of the ESA_RT study (Sreerekha et al., 2006). It focused on three applications: nowcasting, global NWP, and climate studies. The study argues that present-day NWP and future climate studies have similar resolution requirements. The justification for this is that by the time of the instrument launch, climate GCMs are expected to run at resolutions similar to those of presentday NWP GCMs.

The results of the study for cloud ice requirements are summarized in part (b) of Table I. For nowcasting, the requirements on spatial resolution, observation cycle, and delay were found to be even more challenging than for aviation meteorology. For NWP and climate applications, the study confirmed the minimum requirement on IWC and IWP horizontal resolution of $250 \mathrm{~km}$, but proposed to reduce the maximum requirement to $10 \mathrm{~km}$. For the IWC vertical resolution, the maximum requirement was kept at $0.3 \mathrm{~km}$, but the minimum requirement was tightened from 5 to $3 \mathrm{~km}$. Other IWC requirements were retained from the CEOS table.

For IWP an important change in the accuracy requirements was proposed. The change is in the minimum requirement, which was relaxed from $20 \mathrm{~g} \mathrm{~m}^{-2}$ in the CEOS table to $200 \mathrm{~g} \mathrm{~m}^{-2}$. The rationale for this is that thick ice clouds can have IWP values exceeding $3000 \mathrm{~g} \mathrm{~m}^{-2}$, so that observations with an accuracy of $200 \mathrm{~g} \mathrm{~m}^{-2}$ would be useful at least in spotting rather thick clouds.

Like the CEOS table, the ESA_RT study did not discuss requirements for ice particle size information. However, it did discuss requirements for other meteorological 
Table I. Pure scientific requirements for cloud ice measurements.

\begin{tabular}{|c|c|c|c|c|c|c|}
\hline Parameter & $\begin{array}{l}\text { Horizontal } \\
\text { resolution }(\mathrm{km})\end{array}$ & $\begin{array}{c}\text { Vertical } \\
\text { resolution }(\mathrm{km})\end{array}$ & Accuracy & $\begin{array}{l}\text { Obs. cycle } \\
\text { (h) }\end{array}$ & $\begin{array}{l}\text { Delay } \\
\text { (h) }\end{array}$ & Application \\
\hline \multicolumn{7}{|c|}{ (a) CEOS database, WMO/WCRP requirements, discussed in section 3.3} \\
\hline IWC & $50-100$ & $0.15-0.6$ & $10-25 \%$ & $1-3$ & $1-2$ & Aviation meteorology \\
\hline IWC & $10-250$ & $0.3-10$ & $5-20 \%$ & $0.5-12$ & $0.5-2$ & Regional NWP \\
\hline IWC & $50-250$ & $0.3-10$ & $5-20 \%$ & $1-12$ & $1-4$ & Global NWP \\
\hline IWC & $50-250$ & $1-5$ & $5-20 \%$ & $3-12$ & $\mathrm{n} / \mathrm{a}$ & GEWEX \\
\hline IWP & $10-250$ & $\mathrm{n} / \mathrm{a}$ & $10-20 \mathrm{~g} \mathrm{~m}^{-2}$ & $0.5-12$ & $0.5-2$ & Regional NWP \\
\hline IWP & $50-250$ & $\mathrm{n} / \mathrm{a}$ & $10-20 \mathrm{~g} \mathrm{~m}^{-2}$ & $1-12$ & $1-4$ & Global NWP \\
\hline IWP & $50-250$ & $\mathrm{n} / \mathrm{a}$ & $10-20 \mathrm{~g} \mathrm{~m}^{-2}$ & $3-12$ & $\mathrm{n} / \mathrm{a}$ & GEWEX \\
\hline \multicolumn{7}{|c|}{ (b) Additional requirements from ESA_RT study, discussed in section 3.4} \\
\hline IWC & $1-5$ & $0.1-0.5$ & $0.1-0.2 \mathrm{~g} \mathrm{~kg}^{-1}$ & $0.2-0.5$ & $0.1-0.5$ & Nowcasting \\
\hline IWC & $10-250$ & $0.3-3$ & $5-20 \%$ & $1-12$ & $1-4$ & Future global NWP \\
\hline IWC & $10-250$ & $0.3-3$ & $5-20 \%$ & $1-12$ & $\mathrm{n} / \mathrm{a}$ & Future global climate \\
\hline IWP & $10-250$ & $\mathrm{n} / \mathrm{a}$ & $10-200 \mathrm{~g} \mathrm{~m}^{-2}$ & $1-12$ & $1-4$ & Future global NWP \\
\hline IWP & $10-250$ & $\mathrm{n} / \mathrm{a}$ & $10-200 \mathrm{~g} \mathrm{~m}^{-2}$ & $1-12$ & $\mathrm{n} / \mathrm{a}$ & Future global climate \\
\hline \multicolumn{7}{|c|}{ (c) Additional requirements from this study, discussed in section 3.5. } \\
\hline IWC & $0.01-50$ & $0.1-3$ & $10-100 \%$ & $0.5-12$ & $\mathrm{n} / \mathrm{a}$ & Science applications \\
\hline IWC & $1-50$ & $0.1-3$ & $10-100 \%$ & $0.5-12$ & $0.5-2$ & Future regional NWP \\
\hline IWC & $1-50$ & $0.1-3$ & $10-100 \%$ & $0.5-24$ & $\mathrm{n} / \mathrm{a}$ & Future regional climate \\
\hline IWP & $0.01-50$ & $\mathrm{n} / \mathrm{a}$ & $10-100 \%$ & $0.5-12$ & $\mathrm{n} / \mathrm{a}$ & Science applications \\
\hline IWP & $1-50$ & $\mathrm{n} / \mathrm{a}$ & $10-100 \%$ & $0.5-12$ & $0.5-2$ & Future regional NWP \\
\hline IWP & $1-50$ & $\mathrm{n} / \mathrm{a}$ & $10-100 \%$ & $0.5-24$ & $\mathrm{n} / \mathrm{a}$ & Future regional climate \\
\hline$z_{\mathrm{me}}$ & $0.01-50$ & $\mathrm{n} / \mathrm{a}$ & $0.1-3 \mathrm{~km}$ & $0.5-12$ & $\mathrm{n} / \mathrm{a}$ & Science applications \\
\hline$z_{\mathrm{me}}$ & $1-50$ & $\mathrm{n} / \mathrm{a}$ & $0.1-3 \mathrm{~km}$ & $0.5-12$ & $0.5-2$ & Future regional NWP \\
\hline$z_{\mathrm{me}}$ & $1-50$ & $\mathrm{n} / \mathrm{a}$ & $0.1-3 \mathrm{~km}$ & $0.5-24$ & $\mathrm{n} / \mathrm{a}$ & Future regional climate \\
\hline$D_{\text {me }}$ profile & $0.01-50$ & $0.1-3$ & $5-50 \mu \mathrm{m}$ & $0.5-12$ & $\mathrm{n} / \mathrm{a}$ & Science applications \\
\hline$D_{\text {me }}$ profile & $1-50$ & $0.1-3$ & $5-50 \mu \mathrm{m}$ & $0.5-12$ & $0.5-2$ & Future regional NWP \\
\hline$D_{\text {me }}$ profile & $1-50$ & $0.1-3$ & $5-50 \mu \mathrm{m}$ & $0.5-24$ & $\mathrm{n} / \mathrm{a}$ & Future regional climate \\
\hline$D_{\text {me }}$ profile & $10-250$ & $0.3-3$ & $5-50 \mu \mathrm{m}$ & $1-12$ & $1-4$ & Future global NWP \\
\hline$D_{\text {me }}$ profile & $10-250$ & $0.3-3$ & $5-50 \mu \mathrm{m}$ & $1-24$ & $\mathrm{n} / \mathrm{a}$ & Future global climate \\
\hline$D_{\text {me }}$ column & $0.01-50$ & $\mathrm{n} / \mathrm{a}$ & $5-50 \mu \mathrm{m}$ & $1-12$ & $\mathrm{n} / \mathrm{a}$ & Science applications \\
\hline$D_{\text {me }}$ column & $1-50$ & $\mathrm{n} / \mathrm{a}$ & $5-50 \mu \mathrm{m}$ & $1-12$ & $1-4$ & Future regional NWP \\
\hline$D_{\text {me }}$ column & $1-50$ & $\mathrm{n} / \mathrm{a}$ & $5-50 \mu \mathrm{m}$ & $1-24$ & $\mathrm{n} / \mathrm{a}$ & Future regional climate \\
\hline$D_{\text {me }}$ column & $10-250$ & $\mathrm{n} / \mathrm{a}$ & $5-50 \mu \mathrm{m}$ & $1-12$ & $1-4$ & Future global NWP \\
\hline$D_{\text {me }}$ column & $10-250$ & $\mathrm{n} / \mathrm{a}$ & $5-50 \mu \mathrm{m}$ & $1-24$ & $\mathrm{n} / \mathrm{a}$ & Future global climate \\
\hline
\end{tabular}

In (a), requirements for different altitude regions have been combined, since they are nearly identical. See sections 2.1.2 and 3.5.2 for parameter definitions.

observations that are relevant in the context of ice clouds. These are summarized in section 3.6.

The study assumed similar observation cycle requirements for IWC and IWP for future global NWP and climate applications (12 h minimum requirement). However, one can argue that a minimum requirement of $24 \mathrm{~h}$ would still be sufficient to derive simple climatologies.

\subsection{Additional cloud ice requirements}

Applications of cloud data and their requirements were discussed with the study consultants and other selected members of the NWP and climate community. The results are summarized in part (c) of Table I, and are discussed in the following subsections.

\subsubsection{Requirements on IWP}

Currently, the only estimates of IWP from several years of satellite observations are for large-scale semitransparent cirrus clouds (see section 2.2.2). No estimates exist for the IWP in mixed-phase clouds or the total amount of ice in the atmosphere, with the exception of rough estimates of the mean IWP of non-precipitating cold clouds $\left(70 \mathrm{~g} \mathrm{~m}^{-2}\right.$ globally and $100 \mathrm{~g} \mathrm{~m}^{-2}$ in the Tropics) from four months of combined International Satellite Cloud Climatology Project (ISCCP) and Special Sensor Microwave/Imager (SSM/I) data (Lin and Rossow, 1997).

In the absence of more accurate and general measurements, GCMs adjust their cloud microphysical parametrizations until the global annual mean radiation budget at the top of the atmosphere (TOA) is matched within a couple of $\mathrm{W} \mathrm{m}^{-2}$. Therefore, the IWP varies by a factor of 10 between different GCMs (John and Soden, 2006). All GCMs, however, match the cloud radiative forcing from the Earth Radiation Budget Experiment (ERBE) and Clouds and the Earth's Radiant Energy System (CERES) satellites at the TOA within $\pm 5 \mathrm{~W} \mathrm{~m}^{-2}$. This is only possible because errors in IWP can be 
compensated by errors in ice crystal size and cloud altitude.

Ice crystal size is a free parameter in climate models, because empirical relationships that relate ice crystal size to IWP or temperature yield differences in ice crystal size by almost a factor 4 for an ice water content of $0.05 \mathrm{~g} \mathrm{~m}^{-3}$ and by almost an order of magnitude for an ice water content of $1 \mathrm{~g} \mathrm{~m}^{-3}$ (Figure 4). However, ice particle size influences not only the radiative properties, but also the ice sedimentation velocity, therefore it is important that the size assumptions in the models are correct.

The relationship in Figure 4 has already been explored in the range up to about $0.1 \mathrm{~g} \mathrm{~m}^{-3}$ using IR and SW satellite data (Stubenrauch et al., 2007), but the important discrepancies between parametrizations for larger IWC will only be solved with the help of a mission using submillimetre wavelengths.

When IWP estimates from space become available, the amount of condensed water in the ice phase will be restricted in GCMs, and GCMs will then be forced to adjust to the radiation budget by varying ice crystal size and/or cloud altitude. This will force the GCMs to predict the right IWP for the right reasons, which will increase the confidence for climate predictions. The exact consequences for the predicted hydrological cycle and radiation budget cannot be predicted offhand. It is therefore difficult to derive quantitative requirements for the IWP accuracy, however, given the present large uncertainty, a reasonable estimate is that IWP information between 10 and $100 \%$ accuracy will provide a significant model constraint.

As to resolution requirements, the maximum horizontal resolution requirement of $1 \mathrm{~km}$ for IWC and IWP data for future regional NWP and climate applications comes from the scale of convective cells, which is $1-2 \mathrm{~km}$. For science applications, there is no real limit for the maximum horizontal resolution requirement, since data with resolutions down to the metre range would be

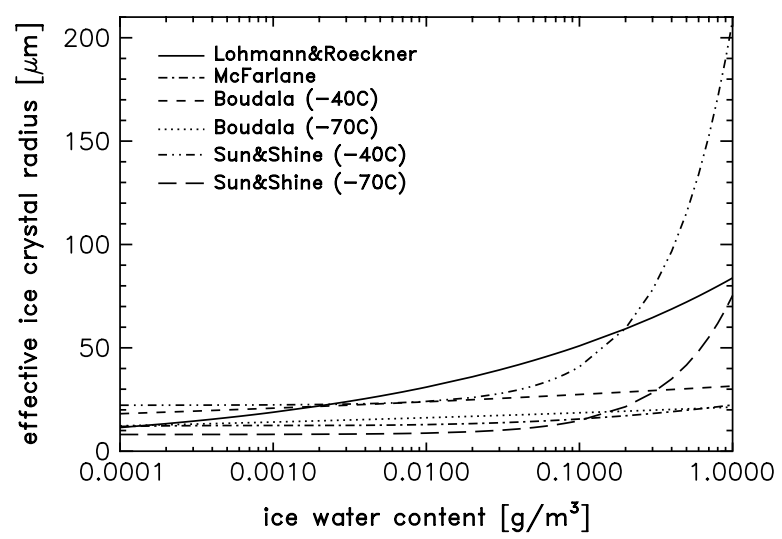

Figure 4. Different parametrizations of effective ice crystal radius as a function of ice water content. The parametrizations were taken from Lohmann and Roeckner (1996), McFarlane et al. (1992), Boudala et al. (2002), and Sun and Shine (1994). For those parametrizations that depend on temperature in addition to the ice water content, two different temperatures $\left(-40^{\circ} \mathrm{C}\right.$ and $\left.-70^{\circ} \mathrm{C}\right)$ were applied. scientifically very valuable for the development and validation of cloud-resolving models. The maximum requirement was therefore set to $10 \mathrm{~m}$.

For the observation cycle there is also a large range between minimum and maximum requirement. A minimum requirement of $24 \mathrm{~h}$ would still provide useful information for climate applications, while even a maximum requirement of $0.5 \mathrm{~h}$ would still provide a benefit for most applications.

\subsubsection{Requirements on cloud altitude}

If an observing system can deliver IWP, but not IWC profiles, it may still be able to deliver important information on the vertical location of the cloud ice mass. An appropriate parameter to describe this is the median IWP cloud altitude, $z_{\text {me }}$, in kilometres. Half of the ice mass will be below $z_{\mathrm{me}}$, the other half above $z_{\mathrm{me}}$. Horizontal resolution and observation cycle requirements of $z_{\text {me }}$ are identical to those for IWP. The accuracy requirements corresponds to the vertical resolution requirement for IWC profiles, $0.1(3 \mathrm{~km})^{-1}$.

\subsubsection{Requirements on particle size}

One reason for the discrepancies in cloud ice water content between different climate models is that the models make different assumptions on ice particle fall velocities. These depend on the ratio of the particle mass to its area perpendicular to the fall direction. Heymsfield and Iaquinta (2000) have shown how this dependence can be parametrized as a function of the particle size. Thus, information on the effective particle size $D_{\text {me }}$ can be used to derive direct information on the effective ice particle fall speeds. Figure 5 demonstrates the correlation between $D_{\text {me }}$ and the mean mass-weighted fall speed $v_{\mathrm{m}}$ of ice particle populations. The speed $v_{\mathrm{m}}$ is the crucial one for the downward ice mass transport, not the fall speeds of individual ice particles.

Resolution, observation cycle, and delay requirements for $D_{\text {me }}$ come from the demand to have the information which is simultaneous with the IWC or IWP information.

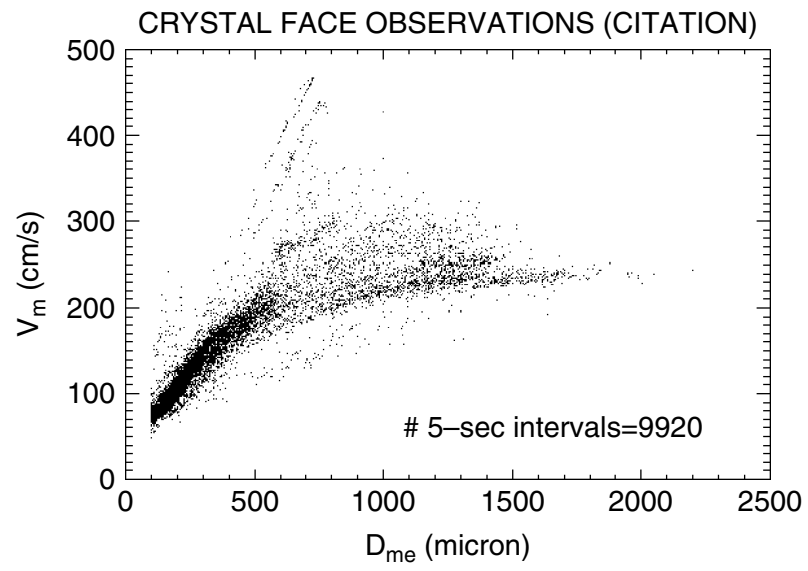

Figure 5. A scatter plot of ice particle fall velocity versus effective size $D_{\text {me }}$ for data taken during CRYSTAL FACE. 
Table II. Requirements on auxiliary parameters for use in scientific studies with submillimetre cloud ice data, derived in the ESA_RT and earlier studies.

\begin{tabular}{|c|c|c|c|c|}
\hline Parameter & $\begin{array}{l}\text { Horizontal } \\
\text { resolution } \\
\quad(\mathrm{km})\end{array}$ & $\begin{array}{l}\text { Vertical } \\
\text { resolution } \\
\quad(\mathrm{km})\end{array}$ & Accuracy & How met \\
\hline $\begin{array}{l}\text { Temperature } \\
\text { profile }\end{array}$ & $10-500$ & $0.3-3$ & $0.5-2 \mathrm{~K}$ & $\begin{array}{l}\text { Clear: IR radiances from advanced polar } \\
\text { (e.g. IASI) and geostationary (e.g. MSG) } \\
\text { sensors, supplemented by MW radiances; } \\
\text { Cloudy: MW radiances, RO. }\end{array}$ \\
\hline $\begin{array}{l}\text { Humidity } \\
\text { profile }\end{array}$ & $10-500$ & $0.3-3$ & $5-20 \%$ & $\begin{array}{l}\text { Clear: IR radiances from advanced sensors, } \\
\text { supplemented by MW radiances and RO; } \\
\text { Cloudy: MW radiances, RO. }\end{array}$ \\
\hline TWV & $10-500$ & $\mathrm{n} / \mathrm{a}$ & $1-5 \mathrm{~kg} \mathrm{~m}^{-2}$ & MW radiances \\
\hline Cloud cover & $10-250$ & $\mathrm{n} / \mathrm{a}$ & $5-10 \%$ & IR multi-spectral \\
\hline LWP & $10-250$ & $\mathrm{n} / \mathrm{a}$ & $10-100 \mathrm{~g} \mathrm{~m}^{-2}$ & MW radiances \\
\hline LWC & $10-250$ & $0.5-3$ & $5-50 \%$ & MW radiances \\
\hline PRL & $10-100$ & $\mathrm{n} / \mathrm{a}$ & $0.1-1 \mathrm{~mm} \mathrm{~h}^{-1}$ & Rain radar, MW radiances \\
\hline PRS & $10-100$ & $\mathrm{n} / \mathrm{a}$ & $0.1-1 \mathrm{~mm} \mathrm{~h}^{-1}$ & Rain radar, MW radiances \\
\hline 3D wind profile & $10-500$ & $0.5-3$ & $1-8 \mathrm{~m} \mathrm{~s}^{-1}$ & Atmospheric motion vectors \\
\hline
\end{tabular}

Acronyms: $\mathrm{IR}=$ infrared, $\mathrm{MW}=$ microwave, $\mathrm{RO}=$ radio occultation,

IASI = Infrared Atmospheric Sounding Instrument, MSG = Meteosat Second Generation,

TWV = total column water vapour, LWP = cloud liquid water path (total column liquid water),

$\mathrm{LWC}=$ cloud liquid water content, PRL $=$ precipitation rate liquid, PRS $=$ precipitation rate solid.

For brevity, observation cycle and delay requirements are not listed here, since they would follow to a large extent from the submillimetre data used.

The requirements on $D_{\text {me }}$ measurement accuracy come from the size of the observed variations in $D_{\text {me }}$. A more detailed discussion of $D_{\text {me }}$ accuracy requirements follows below in section 3.7.4.

For case-studies, more detailed data on cloud microphysics, such as full size and shape distributions, would be very desirable. However, these parameters appear to be beyond the scope of a global satellite mission and are best measured by in situ instruments.

\subsection{Auxiliary parameters}

This section briefly lists auxiliary parameters that are expected to play an important role in the analysis and interpretation of submillimetre ice cloud data. These are data on temperature, humidity, cloud cover, cloud liquid water, precipitation, and winds. Table II lists the requirements identified in the ESA_RT study for these parameters, for future global NWP and climate applications. Spatial resolution requirements for regional applications will be higher, consistent with the higher resolution requirements for regional applications in Table I. These requirements appear adequate for scientific studies with the submillimetre data. It is assumed that they can be met by other sensors, as indicated in Table II.

There is another set of requirements for auxiliary parameters: those parameters that are needed for submillimetre data processing. These parameters are listed in Table III. The current prototype retrieval systems do not use much a priori information, with the exception that most simulations assume a temperature profile knowledge of $1 \mathrm{~K}$ and a surface emissivity knowledge of 0.03. (This applies to the simulations based on the Colorado training dataset, e.g. Buehler (2005), Evans et al. (2002, 2005), and most simulations in the present study.) The surface emissivity information has an impact only on the usage of the data from the surface channel at $243 \mathrm{GHz}$.

\subsection{Breakthrough ranges and scientific mission} requirements

As explained in section 3.2, pure scientific requirements depend on application and are independent of technology,

Table III. Auxiliary parameters necessary for submillimetre data retrieval.

\begin{tabular}{|c|c|c|c|c|}
\hline Parameter & $\begin{array}{l}\text { Horizontal } \\
\text { resolution } \\
(\mathrm{km})\end{array}$ & $\begin{array}{l}\text { Vertical } \\
\text { resolution } \\
\quad(\mathrm{km})\end{array}$ & Accuracy & How met \\
\hline $\begin{array}{l}\text { Temperature } \\
\text { profile }\end{array}$ & $10-500$ & $0.3-3$ & $0.5-2 \mathrm{~K}$ & $\begin{array}{l}\text { Clear: IR radiances, supplemented by MW radiances; } \\
\text { Cloudy: MW radiances }\end{array}$ \\
\hline $\begin{array}{l}\text { Surface } \\
\text { emissivity }\end{array}$ & $10-500$ & $\mathrm{n} / \mathrm{a}$ & $0.01-0.1$ & $\begin{array}{l}\text { Ocean: Wind-dependent emissivity models; } \\
\text { Land: Surface emissivity maps }\end{array}$ \\
\hline
\end{tabular}


cost, and other missions. Technical instrument and mission requirements can not be directly derived from these pure scientific requirements, because, firstly, the mission will serve different applications, and secondly, the synergy with other missions has to be taken into account.

For mission sizing one needs a set of scientific mission requirements, i.e. a set of requirements on the observations that is specific for a submillimetre cloud mission. We achieve this by discussing here likely requirement breakthrough ranges. These are the ranges between minimum and maximum requirement, where there is the steepest gradient in the benefit as a function of cost (Figure 6). Figure 7 illustrates how the different requirement terms are related, and shows the workflow from the pure scientific requirements to the scientific mission requirements.

It is obviously not possible to derive the breakthrough ranges in a rigorous way. However, the concept is still

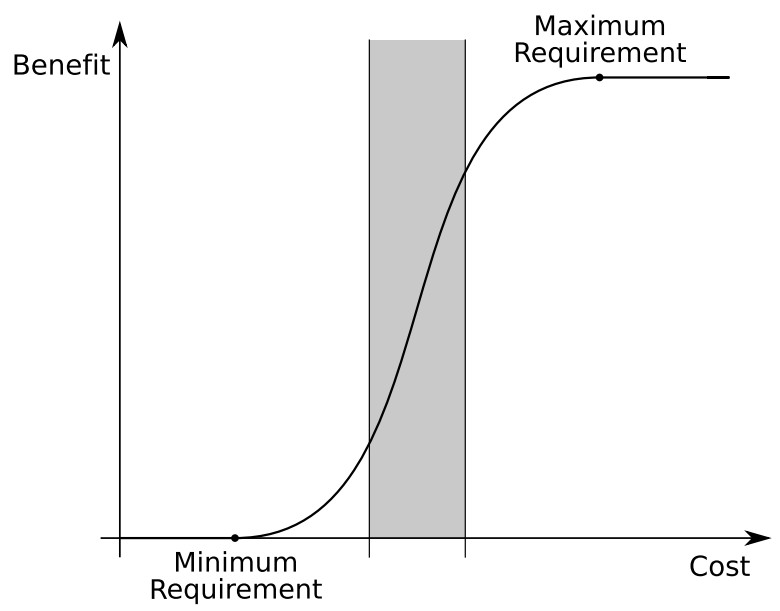

Figure 6. Schematic illustration of the breakthrough range, marked by the shaded area. A mission that performs close to the minimum requirement is unlikely to be cost-effective, because the benefit is too small. A mission that performs close to the maximum requirement is also unlikely to be cost effective, because the cost is too high.

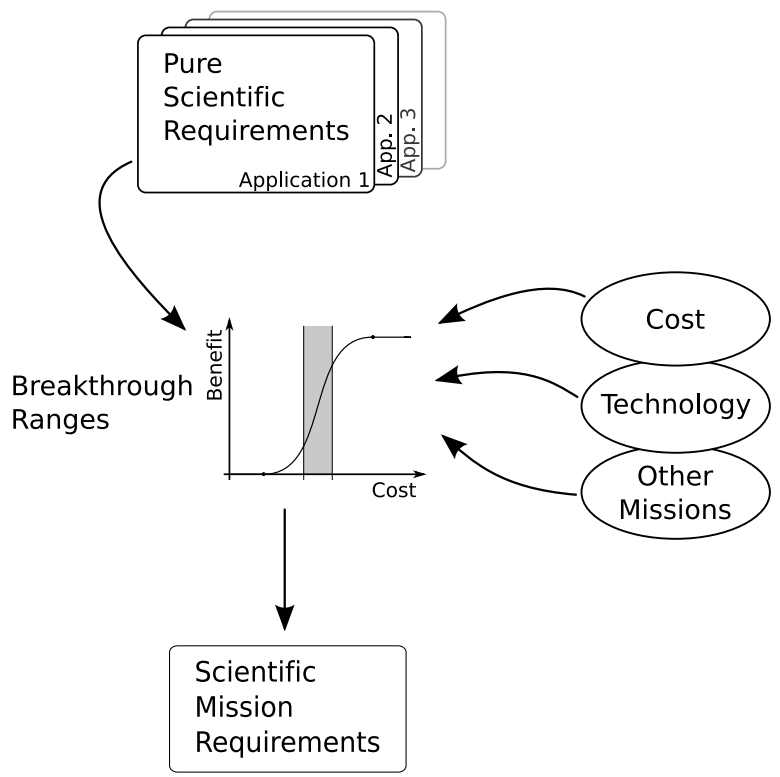

Figure 7. Schematic illustration of how the different terms used in this section are related. The scientific mission requirements are defined as the breakthrough ranges in the pure scientific requirements.

useful. The exercise is particularly necessary for a cloud ice mission, because maximum and minimum scientific requirements can be very far apart for parameters that are not covered by the existing global observing system. A mission designed to meet only the minimum requirement is not likely to be useful. Likewise, a mission designed for the maximum requirement is likely to be prohibitively expensive.

Subsequent paragraphs discuss individual parameters. A summary is given in Table IV.

\subsubsection{Other available data}

It is assumed here that the cloud ice data from the other sensors (discussed in section 2.2) are available at the time of the mission. To be useful, submillimetre data must offer a benefit on top of these existing data. There are

Table IV. Scientific mission requirements for a passive submillimetre-wave cloud ice mission, derived from breakthrough ranges in the pure scientific requirements for cloud ice observations.

\begin{tabular}{lcc}
\hline Parameter & Requirement & Remark \\
\hline IWP accuracy & $10-50 \%$ relative & Maximum of relative accuracy \\
& with $1-10 \mathrm{~g} \mathrm{~m} \mathrm{~m}^{-2}$ threshold & and theshold \\
$z_{\text {me }}$ accuracy & $100-500 \mathrm{~m}$ & $10-50 \mu \mathrm{m}$ \\
$D_{\text {me accuracy }}$ & Global/near global \\
Spatial coverage & $5-20 \mathrm{~km}$ & Fixed local time $( \pm 0.5 \mathrm{~h})$ \\
Horizontal resolution & $6-24 \mathrm{~h}$ & Only for NWP \\
Diurnal sampling & $1-4 \mathrm{~h}$ \\
Observation cycle & $7-1$ years \\
Delay & & \\
Observation time period & &
\end{tabular}

The delay range refers to NWP applications, since for climate and GCM validation/development applications the delay is not critical.

The accuracy requirement for IWP is the maximum of relative accuracy and threshold for each IWP value.

The horizontal resolution requirements assume continuous coverage, which will require an appropriate footprint overlap for a sensor implementing the requirements. 
two important datasets to be considered here. One dataset consists of the global IWP data from IR sensors, which can be derived for IWP values below approximately $90 \mathrm{~g} \mathrm{~m}^{-2}$ (Stubenrauch et al., 2004b). The other dataset to be considered is the IWC profiles from active sensors (CPR), which offer high vertical resolution but only a relatively poor IWP accuracy and limited horizontal coverage (Baptista and Leibrandt, 2001; Stephens et al., 2002).

\subsubsection{Horizontal resolution}

As shown in Table I, horizontal resolution requirements depend strongly on application. As an example, the maximum horizontal resolution requirement for IWP is $50 \mathrm{~km}$ for current global NWP, $10 \mathrm{~km}$ for future global NWP and climate applications, and $1 \mathrm{~km}$ for nowcasting and future regional applications. The breakthrough range thus depends on which applications are considered to be the primary ones for cloud ice data.

Global NWP and climate applications will benefit from cloud ice data, but the data use is hampered to some extent by the fine spatial structure of ice clouds, due to which they are not very well represented in the models. Regional NWP and climate models, on the other hand, can represent the cloud structures more adequately than global models. Also, valuable synergistic data are available on this scale from other meteorological sensors. Applications on an even smaller scale than the regional one, such as nowcasting and cloud-scale simulations in conjunction with in situ data from measurement campaigns, would also greatly benefit from ice data. However, in that case the requirements on spatial resolution, observation cycle, and delay are exceedingly high.

The breakthrough range for horizontal resolution is thus in the area that allows future regional and climate model applications. It is estimated to range from $\approx 5$ to $20 \mathrm{~km}$. This will allow also global applications, of course, since the requirement for regional applications are higher than for global ones.

\subsubsection{Vertical resolution}

The span between minimum and maximum requirement for vertical resolution in Table I is much narrower than for horizontal resolution. This reflects the fact that the atmosphere is much finer structured vertically than horizontally. For example, temperature changes, which translate into changes in ice microphysics, are much larger vertically than horizontally. Moreover, the vertical scale of cirrus clouds is approximately $1-5 \mathrm{~km}$. Thus, a vertical resolution much poorer than $\approx 3 \mathrm{~km}$ for a future cloud sensor is not expected to be very useful.

For the maximum requirement on vertical resolution, the tables from WMO and earlier studies themselves are somewhat conservative in never giving a maximum requirement that is more demanding than $0.1 \mathrm{~km}$ (for nowcasting). In the strict sense, this maximum requirement is too low, because an even higher vertical resolution would give additional benefit, if not for operational use, then for model validation and development.

The analysis shows that even the minimum requirement of the breakthrough range for profile vertical resolution is unlikely to be reached simultaneously with the requirements for accuracy and coverage. Essentially, the vertical resolution necessary to make cloud profile quantities useful would require sacrifices either in horizontal resolution (by going to a limb geometry), or in IWC accuracy and coverage (by going to an active system).

The requirements of global coverage and high IWP accuracy, without reliance on a priori information on the size distribution, were judged more important than profile information. Profile quantities were therefore not included in the scientific mission requirements.

If high-vertical-resolution data from active sensors were available simultaneously, the combination of both datasets would offer a large benefit. On the one hand, the high-resolution profiles from the active sensor could be expected to considerably improve the retrieval performance for the submillimetre instrument, when used as background information. On the other hand, the passive submillimetre data could be used to better calibrate the IWP retrievals from the active sensor data.

While not being able to deliver high-resolution profiles, a submillimetre mission can deliver cloud altitude information, e.g. the median IWP cloud altitude, $z_{\mathrm{me}}$. The maximum end of the breakthrough range for this quantity is the same as for the vertical resolution of profile quantities, $100 \mathrm{~m}$. For the minimum end of the breakthrough range, it has to be considered that cloud altitude information (cloud-top altitudes) is also available from other sensors. An instrument delivering close to the scientific minimum requirement $(3 \mathrm{~km})$ will therefore not give significant additional information. It is judged that $z_{\text {me }}$ should be measured to better than $500 \mathrm{~m}$ to be in the breakthrough range.

\subsubsection{Accuracy}

For accuracy, the available databases state requirements sometimes as absolute values, and sometimes as relative (percent) values. For quantities with a large dynamic range, such as IWP, these two ways of stating a requirement are not at all equivalent. Figure 8 illustrates this. It shows measurement accuracy versus IWP value, both in logarithmic scale. The heavy line shows a hypothetical (but realistic) instrument performance curve. At high IWP values, the absolute errors are expected to be higher than at low IWP values. On the other hand, at low IWP values the relative errors are expected to be high, with absolute errors approaching a constant.

Thus, neither absolute nor relative errors alone are adequate to describe a real measurement system. The solution is to specify the requirements as a combination of absolute and relative requirement (whichever is larger for a given IWP value). The figure illustrates this by showing 


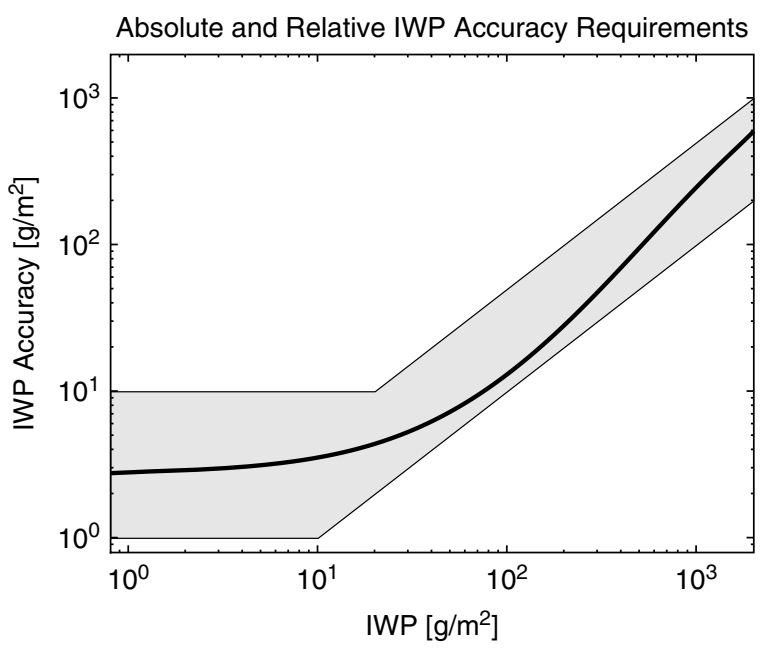

Figure 8. Absolute and relative accuracy requirements for IWP, together with a hypothetical instrument performance curve. See text for more explanation.

as the grey-shaded area a $10-50 \%$ relative requirement range combined with a $1-10 \mathrm{~g} \mathrm{~m}^{-2}$ requirement range for the detection threshold.

While the above arguments were based on the expected performance of a measurement system, one can also argue the case from the point of view of the data application. There are two points to consider here. One is the capability to detect cloud ice, which results in an absolute requirement - the detection threshold. The other point is to measure the amount of ice present, which is better described by a relative requirement. Demanding very high relative accuracy for very low absolute values, or demanding very high absolute accuracy for very high absolute values, is unreasonable.
Table IV contains for IWP a synthesis of the different accuracy requirements in Table I in the threshold and relative accuracy form. The requirements in the CEOS database and defined in the ESA_RT study (Table I) are specified as threshold only and thus differ widely. When a requirement on relative accuracy is added, the requirement for the threshold has to be lowered considerably (see Figure 8). The future regional NWP and climate requirement then translates to requirements of $10-100 \%$ relative accuracy with $1-10 \mathrm{~g} \mathrm{~m}^{-2}$ threshold. We take this as the breakthrough range for IWP accuracy, but tighten the minimum requirement for relative accuracy to $50 \%$ to account for the assumed availability of data with roughly $100 \%$ relative accuracy from active sensors. The minimum of the breakthrough range, $10 \mathrm{~g} \mathrm{~m}^{-2}$ threshold and $50 \%$ relative accuracy, would mean that the full relative accuracy of $50 \%$ is reached at IWP values above $20 \mathrm{~g} \mathrm{~m}^{-2}$. This ensures that there is a sufficiently large overlap in dynamic range to IR measurements, which provide IWP information for IWP values below approximately $90 \mathrm{~g} \mathrm{~m}^{-2}$. The maximum of the breakthrough range, $1 \mathrm{~g} \mathrm{~m}^{-2}$ threshold and $10 \%$ relative accuracy, would mean that the full relative accuracy of $10 \%$ is reached at IWP values above $10 \mathrm{~g} \mathrm{~m}^{-2}$.

The breakthrough range of $1-10 \mathrm{~g} \mathrm{~m}^{-2}$ for the threshold can be justified from CLOUDNET cloud radar data (Figure 9). Although there is a significant number of cloud scenes with very small IWP of $0.1 \mathrm{~g} \mathrm{~m}^{-2}$ or less (Figure 9(a)), these clouds do not contain a significant fraction of the total cloud ice (Figure 9(b)). For a threshold of $10 \mathrm{~g} \mathrm{~m}^{-2}$, we can detect more than $95 \%$ of the total ice mass, and for a threshold of $1 \mathrm{~g} \mathrm{~m}^{-2}$ practically all.
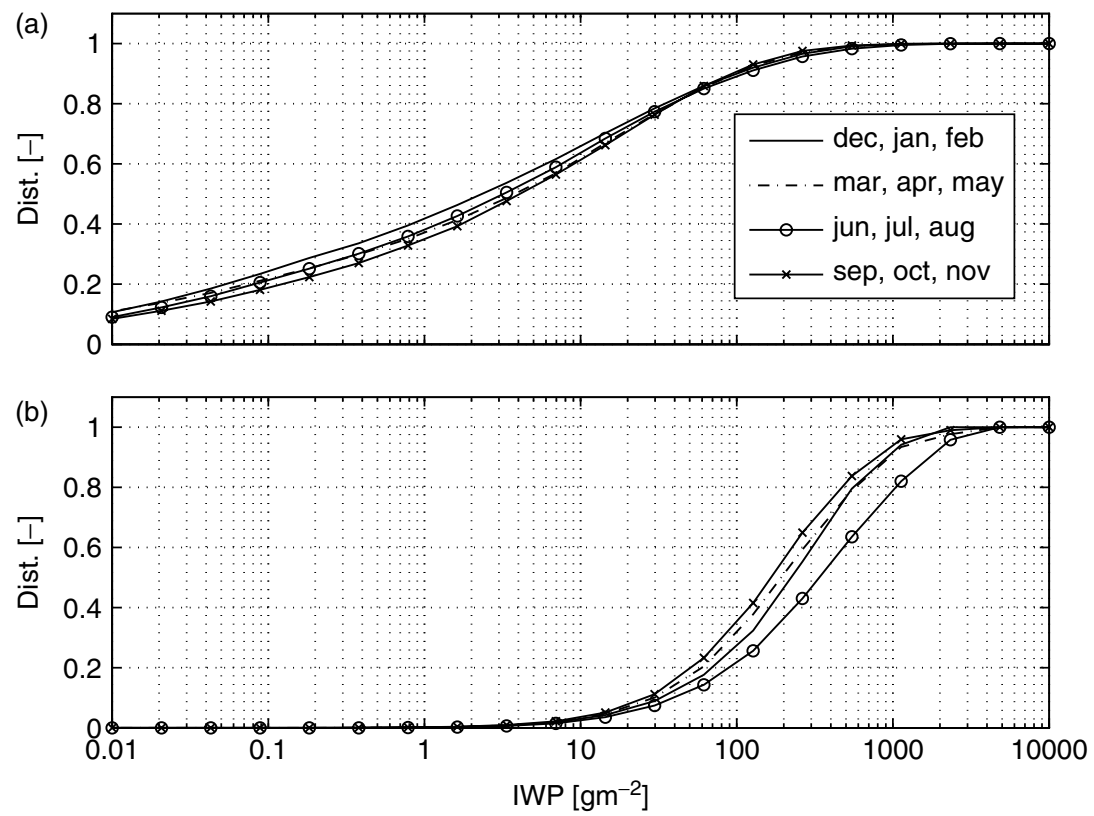

Figure 9. Midlatitude cloud ice statistics from CLOUDNET radar data. (a) cumulative cloud scene fraction. (b) cumulative cloud ice mass fraction. 
For the effective particle size $D_{\mathrm{me}}$, a simple requirement on the absolute measurement accuracy is appropriate, since the $D_{\text {me }}$ value will always be between approximately 20 and $600 \mu \mathrm{m}$ (Garrett et al., 2005; Donovan, 2003). Garrett et al. (2005) describe that the effective size of ice particles in a tropical convective cirrus changed by a factor of 2 across the cloud. Hence, expected variations in $D_{\text {me }}$ are not orders of magnitude, as for IWP, but smaller. The minimum requirement on $D_{\text {me }}$ accuracy must therefore not be too loose. On the other hand, it makes no sense to demand extremely high accuracy for the $D_{\text {me }}$ measurement, without detailed information on the full size and shape distributions. The latter point can also be argued from the point of view of ice particle fall velocities, since the fall speed is not very sensitive to small changes in $D_{\text {me }}$ (compare Figure 5 and Heymsfield and Iaquinta (2000)).

These considerations lead to a breakthrough range for $D_{\text {me }}$ observations of $10-50 \mu \mathrm{m}$ accuracy. In other words, the accuracy range of $5-50 \mu \mathrm{m}$ from Table $\mathrm{I}$ is more or less retained as the scientific mission requirement range in Table IV, only the maximum requirement is relaxed slightly to $10 \mu \mathrm{m}$.

\subsubsection{Observation cycle and spatial coverage}

The issue of observation cycle is linked to the issue of spatial coverage. The scientific requirements from the WMO and later studies (Table I) do not say anything about coverage, because in the strict sense of the definition, the minimum requirement for coverage is very small (for example, even data over Europe alone would not be useless) and the maximum requirement is global coverage. Thus, it makes more sense to discuss coverage here in the context of breakthrough ranges. As demonstrated by John and Soden (2006), large discrepancies can be found in the representation of cloud ice in different circulation models at all latitudes. Since the objective of a submillimetre ice cloud mission is to deliver the data that are necessary to resolve these discrepancies, global coverage is highly desirable. The breakthrough range for coverage is thus set to global or near-global, where near-global means global with some small gaps. The gaps should not always be in the same geographical area. For example, gaps between individual sensor swaths could be tolerated, but missing the polar regions entirely would reduce the benefit significantly. Table IV also summarizes the breakthrough ranges of spatial coverage and other general observation requirements.

For the observation cycle, it is difficult to define a breakthrough range, as this is not expected to improve continuously with increasing cost, but in discrete jumps. The $12 \mathrm{~h}$ minimum requirement from Table I was judged to be too strict, especially for climate applications. It is therefore relaxed here to $24 \mathrm{~h}$. Since the general observation requirements demand near-global coverage, a faster observation cycle can only be achieved by adding a second satellite, accompanied by a significant jump in cost. The observation cycle would then jump to 12 or $6 \mathrm{~h}$. There would indeed also be a big jump in benefit because, especially with $6 \mathrm{~h}$ observation cycle, new applications focusing on the diurnal cycle of ice clouds become possible. The jumps in benefit for an even faster observation cycle are not as big as this first one, so the observation cycle breakthrough range is defined as 6-24 h.

An issue that then has to be discussed is diurnal sampling. There are known to be diurnal cycles in cloudiness, particularly for convective cloud types. There are two strategies to address this issue in a satellite mission, either to make the sampling of the diurnal cycle a mission objective, or to eliminate its influence on the measurement by measuring at fixed local time. The scientific minimum requirement is the observation at a fixed local time, and the maximum requirement is full coverage of the diurnal cycle. But the issue of diurnal cycle coverage is linked to the issues of spatial coverage and observation cycle. With the given breakthrough ranges of these parameters, measurements at different local times would lead to an aliasing problem, rather than to desirable additional information. The breakthrough range for diurnal sampling is thus set to fixed local time, plus or minus $0.5 \mathrm{~h}$. This range comes from the requirement that the diurnal cycle should not change significantly between different observations.

\subsubsection{Delay}

Delay requirements are relevant only for operational NWP applications, and not for climatology and model development applications. The $1-4 \mathrm{~h}$ requirement from Table I is firmly established by operational data users and is therefore retained here.

\subsubsection{Observation time period}

As for the spatial coverage, there are no scientific requirements on observation time period in the strict sense, because both NWP and climate applications benefit from an observation time that is as long as possible, while on the other hand even a one-time observation is not useless. Thus, the concept of the breakthrough range is better suited to address this issue. One then has to investigate for which observation time periods there are big jumps in benefit. These will be related to atmospheric cycles of different periodicity.

The first big jump in benefit occurs for an observation time period of 1 year, because it would allow the sampling of the annual cycle. However, this is not satisfactory, firstly because the high variability of cloudiness and the atmospheric state in general means that the representativeness of one year of observation is questionable. Secondly, there is the variability associated with cycles, such as the El Niño Southern Oscillation (ENSO).

Accordingly, the next jump in benefit occurs when one ENSO cycle can be sampled, which requires an observation time period of 5 to 7 years. The breakthrough range for the observation time period in Table IV is therefore set to 7-1 years. 


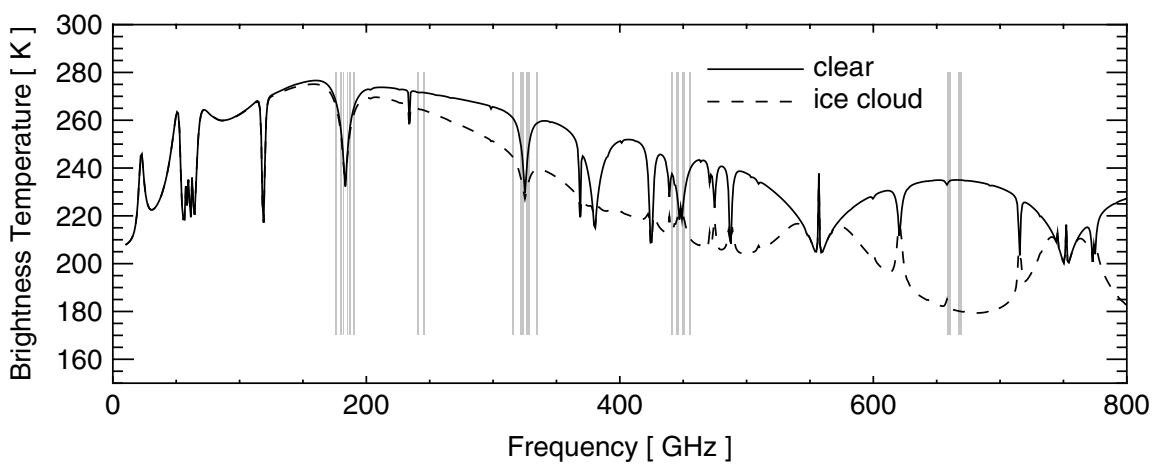

Figure 10. The submillimetre spectrum of a clear-sky and a cloudy midlatitude winter atmosphere, with bars indicating the positions of the prototype instrument channels. A homogeneous cloud was assumed from 8 to $10 \mathrm{~km}$ with an IWC of $0.04 \mathrm{~g} \mathrm{~m}^{-3}$, consisting of spherical ice particles with $100 \mu \mathrm{m}$ radius. The widths of the pass bands are drawn smaller than in reality (compare Table V), so that the individual channels can be distinguished.

\section{Mission concept and performance}

Within the recent ESA study 'Establishment of mission and instrument requirements to observe cirrus clouds at submillimetre wavelengths', retrieval simulations were used to derive an instrument and mission concept that fulfills the scientific mission requirements. The result is presented here. The methodology of the retrieval simulations is described in detail in Jiménez et al. (2007).

\subsection{Instrument and mission concept}

Figure 10 shows the channel positions of the prototype instrument concept, relative to the atmospheric spectrum for clear and cloudy conditions. The configuration that was found optimal is nearly the same as in Buehler (2005), except that the highest frequency channel was dropped. (The rationale for that change is discussed in section 4.2.) A further difference is that the dualpolarization capability of the highest-frequency channels of the original concept was dropped, because retrieval simulations did not provide sufficient proof that polarized measurements give a significant benefit (Jiménez et al., 2007).

Table V lists the channel positions explicitly, along with the performance estimates that were derived by the engineering team in the ESA study (Jarret et al., 2007), under the lead of Sula Systems Ltd, UK. As in the original proposal, the prototype instrument is a conical scanner, which simplifies the data analysis considerably.

Details of the technical implementation will not be discussed here. The interested reader is referred to Jarret et al. (2007). However, Table VI lists some overall characteristics of the prototype instrument. As the table shows, the overall size, mass, and power consumption of the instrument are modest. To fulfill the requirement for simultaneous IR data, the mission will fly in tandem with Metop or another meteorological satellite, which determines the orbit parameters. The earth incidence angle $\left(\approx 53^{\circ}\right)$ of the conical scan is chosen such that the requirement of near-global horizontal coverage in $24 \mathrm{~h}$ is met, without giving up too much vertical coverage
Table V. Channel sets and estimated radiometric performance of the prototype instrument concept developed in Jarret et al. (2007).

\begin{tabular}{cccc}
\hline $\begin{array}{c}\text { Channel } \\
\text { set }\end{array}$ & $\begin{array}{c}\text { Centre frequency } \\
(\mathrm{GHz})\end{array}$ & $\begin{array}{c}\text { IF bandwidth } \\
(\mathrm{GHz})\end{array}$ & $\begin{array}{c}\text { NE } \Delta T \\
(\mathrm{~K})\end{array}$ \\
\hline \multirow{2}{*}{183} & $183.31 \pm 1.5$ & 1.4 & 0.6 \\
& $183.31 \pm 3.5$ & 2.0 & 0.5 \\
& $183.31 \pm 7.0$ & 3.0 & 0.4 \\
243 & $243.2 \pm 2.5$ & 3.0 & 0.5 \\
325 & $325.15 \pm 1.5$ & 1.6 & 1.0 \\
& $325.15 \pm 3.5$ & 2.4 & 0.8 \\
& $325.15 \pm 9.5$ & 3.0 & 0.7 \\
448 & $448.0 \pm 1.4$ & 1.2 & 1.9 \\
& $448.0 \pm 3.0$ & 2.0 & 1.4 \\
& $448.0 \pm 7.2$ & 3.0 & 1.2 \\
664 & $664.0 \pm 4.2$ & 5.0 & 1.5 \\
\hline
\end{tabular}

Table VI. A summary of the main characteristics of the prototype instrument concept developed in Jarret et al. (2007).

\begin{tabular}{ll}
\hline Parameter & Value \\
\hline No. of channels & $\begin{array}{l}12 \\
\text { (in } 11 \text { different frequency bands) }\end{array}$ \\
Polarization & $\begin{array}{l}\text { Single, all bands } \\
\text { All bands: } 15 \mathrm{~km} \times 15 \mathrm{~km} \\
\text { (except } 664 \mathrm{GHz}: 7.5 \mathrm{~km} \times 7.5 \mathrm{~km} \text { ) }\end{array}$ \\
Sampling & $\begin{array}{l}20 \% \text { overlap } \\
\text { (along track and along scan) }\end{array}$ \\
Scan rate & $\approx 33 \mathrm{rpm}$ \\
Earth incidence angle & $\approx 53^{\circ}$ \\
Beam efficiency & $>95 \%$ \\
Mass & $51 \mathrm{~kg}$ \\
Power & $70 \mathrm{~W}$ \\
Overall envelope & $1.0 \mathrm{~m} \times 0.7 \mathrm{~m} \times 0.4 \mathrm{~m}$ \\
\hline
\end{tabular}

of low-altitude clouds, which is a problem for even shallower earth incidence angles.

A remarkable feature of the prototype instrument is that the highest frequency channel at $664 \mathrm{GHz}$ is realized by a pair of radiometers (with fields of view positioned 
orthogonally to the scan direction), so that this channel has twice the spatial resolution of the other channels. Besides the science benefit, this facilitates the use of a single aperture for all channels, since the large reflector then does not have to be so under-illuminated for this channel.

\subsection{Performance relative to retrieval accuracy requirements}

Retrieval simulations were used to test different channel combinations and other instrument options for the prototype instrument concept. The simulations used a neural network $(\mathrm{NN})$, together with a stochastic training dataset of atmospheric states and associated radiances. The training data contained random cloud profiles, including random sizes and shapes of ice particles, with statistics consistent with radar and in situ aircraft data. The methodology and results of these simulations are discussed in detail in Jiménez et al. (2007). Here, we will show only the performance simulation for the selected prototype configuration, and compare the simulated performance to the scientific mission requirements.

The state variables considered are IWP, $D_{\mathrm{me}}$, and $z_{\mathrm{me}}$. Errors are reported as the median of the absolute values of the retrieval errors for all the realizations in the dataset. If relative errors are given, they are calculated as the difference of retrieved and true value divided by the true value. Median absolute errors are used because they are more robust against rare outliers than root mean square (RMS) errors, which are approximately twice the median absolute errors in these simulations.

The performance of the instrument is judged by an error characterization based on simulating only the main random uncertainties in the observing system. This implies that any possible systematic errors related to the forward model or the sensor are assumed to be smaller than the investigated stochastic errors. This assumption is appropriate at the current level of detail of instrumental knowledge. Regarding forward model uncertainties, those assumed to have a larger impact on the retrievals, such as an imperfect knowledge of the temperature or surface emissivity, are added when generating the training datasets. Regarding measurement errors, the sensor is characterized by an effective system temperature for each channel, and its derived noise equivalent temperature $(\mathrm{NE} \Delta \mathrm{T})$ is used as the measurement uncertainty in the simulations. The NE $\Delta \mathrm{T}$ values for each channel are given in Table V.

The system model is a 1D one, which is an established procedure for downlooking sensors. This means that the atmospheric state is assumed to vary only in the vertical, and each instrument pixel is treated independently. Also, sub-pixel structure of the cloud field is neglected. Davis et al. (2006) have shown that in some cases the 3D structure of clouds can have a significant impact on simulated radiances. The dominant effect was found to be that of sub-pixel structure (beam-filling effect), rather than $3 \mathrm{D}$ radiative transfer effects. Despite these known shortcomings of the 1D approach, it was judged to be adequate for a basic mission performance study. This could be refined in later studies.

Simulations were carried out not only for a pure submillimetre instrument, but also for the case that radiances from an IR instrument with channels at 10.7 and $12 \mu \mathrm{m}$ are additionally available for the inversions. The IR channels were assumed to sample identical atmospheres as the submillimetre radiances, that is, collocation between the submillimetre and IR measurements was assumed to be perfect and the propagation path was assumed to be the same. The assumed noise level for both IR channels was $0.6 \mathrm{~mW} \mathrm{~m}^{-2}\left(\mathrm{~cm} \mathrm{sr}^{-1}\right)$, corresponding to approximately $0.5 \mathrm{~K}$ noise at $260 \mathrm{~K}$ scene temperature. It should be mentioned that a further IR channel at about $8.3 \mu \mathrm{m}$ may further improve the performance, especially if ice crystals in cirrus are dominantly aggregates (compare Figure 5 of Rädel et al., 2003), but such a channel was not assumed to be available here.

Figure 11 shows the simulated performance for IWP, $D_{\text {me }}$, and $z_{\text {me. }}$. Retrieval error statistics are plotted for two different atmospheric scenarios, tropical anvil clouds and midlatitude winter synoptic cirrus. For IWP the instruments with and without complementary IR channels meet the scientific mission requirements for both investigated atmospheric scenarios. In the tropical case the instrument with IR channels even slightly outperforms the requirements range for very low IWP values. For $D_{\text {me }}$ the performance is within the scientific mission requirement range, except for very low IWP. Below approximately $20 \mathrm{~g} \mathrm{~m}^{-2}$ IWP the retrieval performance for $D_{\text {me }}$ degrades, in parallel with the performance for IWP itself. The same is true for $z_{\text {me }}$, which is in the requirement range down to IWP values of approximately $20 \mathrm{~g} \mathrm{~m}^{-2}$, below which errors increase sharply. This behaviour for $D_{\mathrm{me}}$ and $z_{\mathrm{me}}$ is expected, since the retrieval will not be able to assign reliable values to these parameters for clouds that are below the detection threshold. The retrieval performance for all three investigated retrieval parameters is therefore judged to be well within the scientific mission requirement range.

Compared to the last CIWSIR mission proposal (Buehler, 2005), the prototype instrument lacks the highest frequency channel at $874.4 \mathrm{GHz}$. As discussed in more detail in Jiménez et al. (2007), this results in an instrument with slightly poorer performance for those situations with thin and high clouds containing very small particles, as is sometimes the case for the tropical simulations. As demonstrated by Figure 11, adding the IR channels improves notably those retrievals, and results in an overall better retrieval performance than the instrument with all submillimetre channels but without additional IR channels. The $874.4 \mathrm{GHz}$ channel was dropped, because based on the simulations it was concluded that it is more advantageous, from a point of view of retrieval performance, to have the means of combining IR radiances with the submillimetre radiances measured with the final configuration of the instrument, rather than having the all-channel instrument but without the possibility of using IR information in the retrievals. 

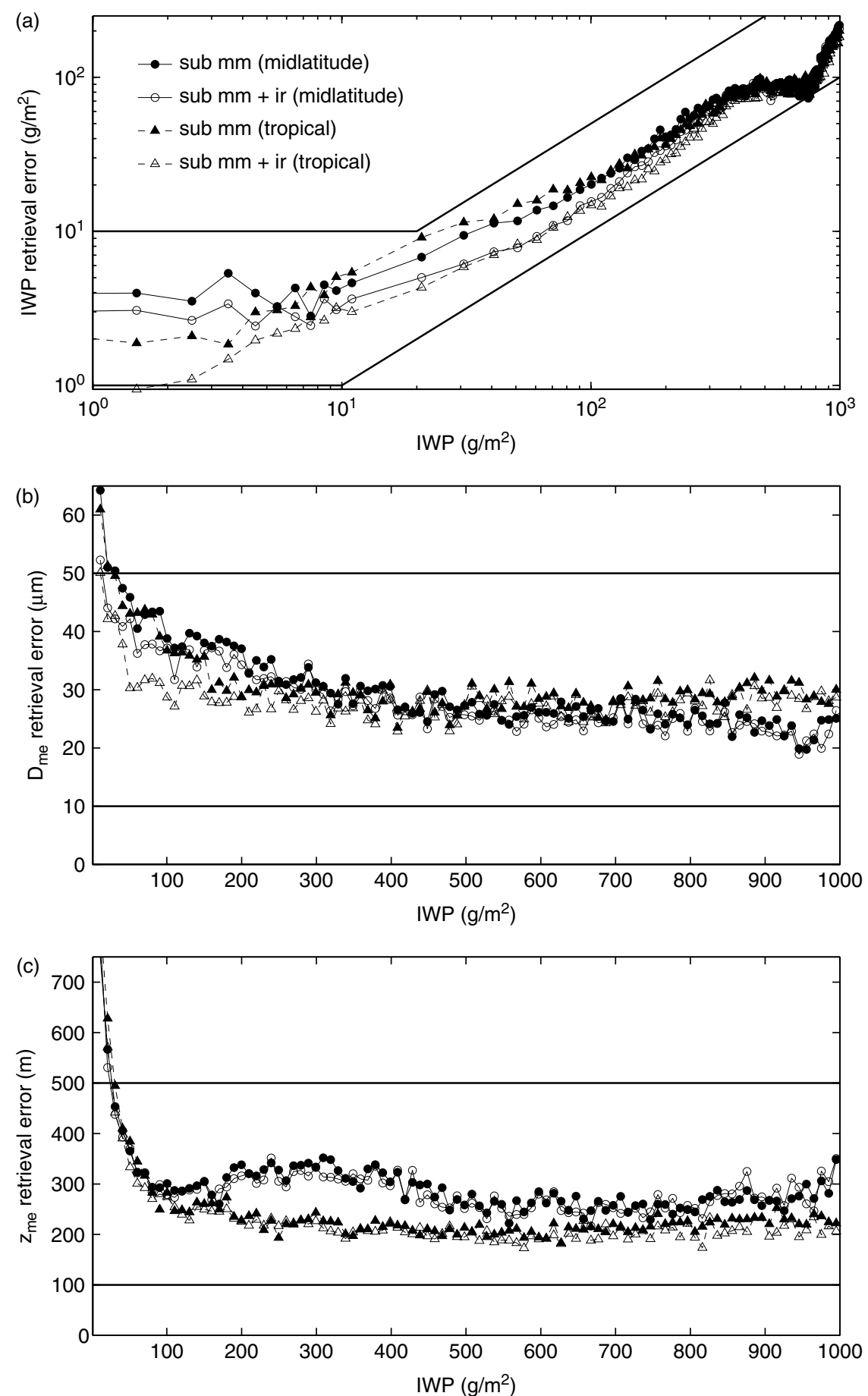

Figure 11. Retrieval performance for (a) ice water path, (b) particle size, and (c) cloud altitude, all as a function of the true IWP. Retrieval results are shown with and without additional infrared channels, as available from Metop. Also shown are results for two different atmospheric scenarios (midlatitude and tropical). Solid black lines indicate the scientific mission requirement ranges.

\subsection{Performance relative to general observation} requirements

The requirements to discuss here are horizontal and vertical resolution, observation cycle and spatial coverage, diurnal sampling, and observation time period.

\subsubsection{Horizontal resolution}

The prototype mission concept offers a horizontal resolution of $15 \mathrm{~km}$ for most channels, which is within the scientific mission requirement range. Because of the large benefit of higher resolution (it allows a better representation of the cloud structure), the concept suggests an enhanced resolution of $7.5 \mathrm{~km}$ for the highest-frequency channel, which brings this channel closer to the high end of the requirement range. This is judged to give a significant scientific benefit. The footprints overlap by $20 \%$, which is important for data resampling and necessary to fulfill the requirement for spatially continuous measurements. 


\subsubsection{Vertical resolution}

Vertical resolution requirements for IWC and $D_{\text {me }}$ profile quantities are very challenging, due to the limited vertical scale of clouds. They can not be met with a passive sensor, thus IWC and $D_{\text {me }}$ profiles should not be primary mission targets. The vertical resolution of the cloud altitude retrieval is judged to be useful (see last section), even though this is not a primary mission target.

\subsubsection{Observation cycle and spatial coverage}

The prototype scanning geometry, in combination with a Metop-type orbit, leads to near-global coverage within $24 \mathrm{~h}$. Coverage is not truly global, because there are gaps at the Equator. This meets the lower end of the scientific mission requirement range. The impact of the gaps is somewhat mitigated by the fact that a large part of the gap areas is in the subtropics, where cloud occurrence is low (e.g. Wylie et al., 1994).

For midlatitudes the coverage is global within $24 \mathrm{~h}$ and for high latitudes it is global within $12 \mathrm{~h}$. Already at $60^{\circ}$, one sometimes gets coverage by consecutive satellite passes, which increase in frequency for even higher latitudes. At $70^{\circ}$, double passes are the rule and triple passes possible, so that one has at least four observations per $24 \mathrm{~h}$. However, the usefulness of these more frequent passes for cloud evolution and daily cycle studies is limited for a single satellite mission, because the samples are not evenly distributed in time.

Overall, the prototype mission concept is judged to meet the observation cycle and coverage requirements. It is at the lower end of the requirement range in the tropics, and at the upper end for high latitudes.

\subsubsection{Diurnal sampling}

The prototype instrument is on a sun-synchronous orbit and thus meets the requirement for fixed local time observations, with a local node time error of 30 minutes. Should the Metop orbit drift, the requirement to fly in tandem with Metop is judged to be more important than the requirement of fixed local time.

\subsubsection{Data delay}

Data delay requirements are not critical, since the proposed mission concept is not primarily for operational meteorology. Nevertheless, it is expected that meteorological agencies will have a high interest in using the data, so their needs should be accommodated as far as possible. For the proposed concept the delay is expected to be close to $4 \mathrm{~h}$, and thus close to the lower end of the requirement range for operational NWP. If interest from the NWP community is strong enough, the addition of direct broadcast capability should be considered.

\subsubsection{Observation time period}

The proposed mission lifetime for the prototype concept is 3 years, somewhat in the middle of the defined scientific mission requirement range. From the scientific point of view, it is highly desirable that a possible longer lifetime is not unnecessarily inhibited by particular design choices.

\section{Summary and conclusions}

The purpose of this paper was to document a complete and stable concept for a satellite mission to provide global cloud ice observations that can resolve the large discrepancies in cloud ice water content among current NWP and climate prediction models. In particular, the paper documents that (a) the scientific requirements for such a mission were derived in a systematic way, taking into account earlier exercises, (b) a technically feasible prototype mission and instrument concept was developed based on these requirements, and (c) the prototype concept does actually meet the requirements.

A summary of the scientific mission requirements is given in Table IV. These requirements were derived by a three-stage process: first existing requirement estimates were gathered from the CEOS of the WMO and from earlier studies. Next, additional requirements for cloud ice observations for different applications were formulated. Finally, the concept of breakthrough ranges was used to derive a comprehensive set of scientific mission requirements from the pure scientific requirements for the different applications. The key target parameters identified in this process were the IWP, $z_{\mathrm{me}}$, and $D_{\mathrm{me}}$.

The analysis of scientific mission requirements took into account two types of other cloud ice information: IWC profiles from active sensors (CPR) and IWP data from IR sensors. Both other sensor types are complementary to a submillimetre ice sensor, one because it can deliver high-vertical-resolution profiles, albeit with limited IWC accuracy (especially at large IWP) and limited horizontal coverage, the other because it can deliver IWP data for thin cirrus. The core parameters of the developed mission concept, IWP for all cloud types and $D_{\text {me }}$, cannot be delivered by any other sensor type.

The prototype instrument and mission concept is a conically scanning 12-channel radiometer, flying in tandem with Metop. The highest observation band is observed by two channels to achieve a higher spatial resolution, so there are altogether 11 different observation bands. Tables V and VI summarize the key parameters of the instrument. Retrieval simulations were used extensively to test the performance of the prototype instrument and many other instrument configurations (Jiménez et al., 2007).

Figure 11 shows a summary of the retrieval performance, relative to the scientific mission requirements. It demonstrates that the prototype instrument meets the requirements. It can measure IWP with a relative accuracy of approximately $20 \%$ and a detection threshold of approximately $2 \mathrm{~g} \mathrm{~m}^{-2}$. The median mass equivalent sphere diameter of the ice particles can be measured with an accuracy of approximately $30 \mu \mathrm{m}$. The 
median IWP cloud altitude can be measured with an accuracy of approximately $300 \mathrm{~m}$. All the above accuracies are median absolute error values; RMS error values are approximately twice as high for these simulations, due to rare outliers.

\section{Acknowledgements}

The mission proposal that was the basis for the work described here was supported by a large international community; a list of contributors can be found in Buehler (2005).

The work described here was partially funded by the European Space Agency (ESA) under the study contract 'Establishment of mission and instrument requirements to observe cirrus clouds at submillimetre wavelengths', ESTEC Contract No. 19053/05/NL/AR. We thank Ulf Klein, the ESA scientist for the study, for his valuable support. Furthermore, we thank Mark Jarret, from Sula Systems Ltd, for fruitful collaboration within the study.

This work is a contribution to COST Action 723 'Data exploitation and modelling for the upper troposphere and lower stratosphere', which has sponsored the publication costs. (More information on the COST program can be found at http://www.cost.esf.org, and more information on COST 723 can be found at http://www.cost723.org.)

Work on concepts for a European submillimetre cloud ice satellite sensor has a several years history at the University of Bremen. After initial ideas by K. Kunzi in 1996, the concept was refined by J. Miao and G. Heygster within the EU project CLOUDS, led by B. Bizzarri. This early work culminated in the first CIWSIR mission proposal to ESA (Kunzi, 2001), from which the second CIWSIR mission proposal in 2005 has inherited many important features.

Last but not least, the authors thank the ARTS radiative transfer community.

\section{References}

Ackerman SA, Starr DO'C, Evans KF, Principe C, Revercomb H, Moran V, Azzolini J, Arur S, Ellis J. 2005. 'Submillimeter Infrared Radiometer Ice Cloud Experiment (SIRICE)'. NASA mission proposal.

Ackerman SA, Starr DO'C, Evans KF, Jackson GS. 2006. 'A unique approach to measuring cloud ice mass from Earth viewing'. Satellites. AGU meeting, San Francisco CA, 11-15 December 2006.

Atlas D, Matrosov SY, Heymsfield AJ, Chou M-D, Wolff DB. 1995. Radar and radiation properties of ice clouds. J. Appl. Meteorol 34: 2329-2345.

Baptista JPVP, Leibrandt W. 2001. 'EarthCARE - Earth Clouds, Aerosols and Radiation Explorer'. Assessment Report, ESA SP1257(1) ESA : Darmstadt, Germany.

Boudala FS, Isaac GA, Fu Q, Cober SG. 2002. Parameterization of effective ice particle size for high-latitude clouds. Int. J. Climatol 22: $1267-1284$.

Buehler SA. 2005. 'Cloud Ice Water Submillimeter Imaging Radiometer (CIWSIR)'. ESA Earth Explorer Mission Proposal. Technical report, University of Bremen, Germany.

Buehler SA, Eriksson P, Kuhn T, von Engeln A, Verdes C. 2005. ARTS, the Atmospheric Radiative Transfer Simulator. J. Quant. Spectrosc. Radiat. Transfer 91: 65-93, DOI: 10.1016/j.jqsrt. 2004.05.051.

Charlton J. (ed.) 2002. 'Study on future microwave and millimetrewave radiometer requirements and concepts'. Final Report, ESTEC contract No. 14841/01/NL/MM. Available through ESA.
Davis CP, Evans KF, Buehler SA, Wu DL, Pumphrey HC. 2006. $3-\mathrm{D}$ polarised simulations of space-borne passive $\mathrm{mm} / \mathrm{sub}-\mathrm{mm}$ midlatitude cirrus observations: a case study. Atmos. Chem. Phys. Discuss. 6: $12701-12728$.

Doms G, Schaettler U. 1999. 'The nonhydrostatic Limited-Area Model LM (Lokal-Modell) of DWD. Part I: Scientific documentation'. GB Forschung und Entwicklung. DWD: Offenbach, Germany.

Donovan DP. 2003. Ice-cloud effective particle size parameterization based on combined lidar, radar reflectivity, and mean Doppler velocity measurements. J. Geophys. Res. 108: D18 DOI: 10.1029/2003JD003469.

Emde C, Buehler SA, Davis C, Eriksson P, Sreerekha TR, Teichmann C. 2004. A polarized discrete ordinate scattering model for simulations of limb and nadir longwave measurements in 1D/3D spherical atmospheres. J. Geophys. Res. 109: D24 DOI: 10.1029/2004JD005140.

Eriksson P, Ekström M, Rydberg B, Murtagh D. 2007. First Odin sub$\mathrm{mm}$ retrievals in the tropical upper troposphere: ice cloud properties. Adv. Chem. Phys. 7: 471-483.

Evans KF, Stephens GL. 1995. Microwave radiative transfer through clouds composed of realistically shaped ice crystals. Part II: Remote sensing of ice clouds. J. Atmos. Sci. 52: 2058-2072.

Evans KF, Walter SJ, Heymsfield AJ, Deeter MN. 1998. Modeling of submillimeter passive remote sensing of cirrus clouds. J. Appl. Meteorol. 37: 184-205.

Evans KF, Walter SJ, Heymsfield AJ, McFarquhar GM. 2002 Submillimeter-wave cloud ice radiometer: Simulations of retrieval algorithm performance.. J. Geophys. Res. 107: D3 DOI: 10.1029/2001JD000709.

Evans KF, Wang JR, Racette PE, Heymsfield G, Li L. 2005. Ice cloud retrievals and analysis with data from the Compact Scanning Submillimeter Imaging Radiometer and the Cloud Radar System during CRYSTAL-FACE. J. Appl. Meteorol. 44: 839-859.

Garrett TJ, Navarro BC, Twohy CH, Jensen EJ, Baumgardner DG, Bui PT, Gerber H, Herman RL, Heymsfield AJ, Lawson P, Minnis P, Nguyen L, Poellot M, Pope SK, Valero FPJ, Weinstock EM. 2005. Evolution of a Florida cirrus anvil. J. Atmos. Sci. 62: 2352-2372.

Gayet J-F, Ovarlez J, Shcherbakov V, Strom J, Schumann U, Minikin A, Auriol F, Petzold A, Monier M. 2004. Cirrus cloud microphysical and optical properties at southern and northern midlatitudes during the INCA experiment. J. Geophys. Res. 109: DOI: 10.1029/2004JD004803.

Golding BW, Atkinson NC. 2002. 'Study of future microwave sounders on geostationary and medium Earth orbits. Task 1 Report: Review of preliminary list of products and corresponding requirements'. ESA study STN/PR72/002, MGO-MET-RP-001. Available through ESA.

Heymsfield AJ. 2003. Properties of tropical and midlatitude ice cloud particle ensembles, Part II: Applications for mesoscale and climate models. J. Atmos. Sci. 60: 2592-2611.

Heymsfield AJ, Iaquinta J. 2000. Cirrus crystal terminal velocities. $J$. Atmos. Sci. 57: 916-938.

Heymsfield AJ, Bansemer A, Schmitt C, Twohy C, Poellot MR. 2004. Effective ice particle densities derived from aircraft data. J. Atmos. Sci. 61: $982-1003$.

Heymsfield AJ, Protat A, Austin RT, Bouniol D, Hogan RJ, Delanoë J, Okamoto H, Sato K, van Zadelhoff GJ, Donovan DP, Wang Z. 2007. Testing IWC retrieval methods using radar and ancillary measurements with in situ data. J. Appl. Meteorol. Climatol. in press.

Hinsman D. 2003. Satellite systems and requirements, CEOS/WMO database, version 2.5 World Meteorological Organization: Geneva. http://www.wmo.int/pages/prog/sat/Databases.html

Hong G, Heygster G, Miao J, Kunzi K. 2005. Detection of tropical deep convective clouds from AMSU-B water vapor channels measurements. J. Geophys. Res. 110: D9, D05205. DOI: 10.1029/2004JD004949.

Houze RA. 1994. Cloud Dynamics. International Geophysics series No. 53, Academic Press.

Jarret M. (ed.) 2007. 'Establishment of mission and instrument requirements to observe cirrus clouds at sub-millimetre wavelengths'. Final Report, ESTEC Contract No. 19053/05/NL/AR. Available from ESA. http://www.sat.ltu.se/projects/submm_cirrus/

Jiménez C, Buehler SA, Rydberg B, Eriksson P, Evans KF. 2007. Performance simulations for a submillimetre-wave cloud ice satellite instrument. Q. J. R. Meteorol. Soc. 133: 129-149.

John VO, Soden BJ. 2006. Does convectively-detrained cloud ice enhance water vapor feedback? Geophys. Res. Lett. 33: L20701, DOI: $10.1029 / 2006$ GL027260. 
Kristjansson JE, Edwards JM, Mitchell DL. 2000. Impact of a new scheme for optical properties of ice crystals on climates of two CGMs. J. Geophys. Res. 105: 10063-10079.

Kunzi K. 2001. Cloud Ice Water Sub-millimetre Imaging Radiometer (CIWSIR): Proposal in response to the second call for proposals for Earth Explorer Opportunity Missions. University of Bremen. http://www.iup.uni-bremen.de/iupage/psa/documents/CISWIR_ proposal_final.pdf

Li J-L, Waliser DE, Jiang JH, Wu DL, Read W, Waters JW, Tompkins AM, Donner LJ, Chern J-D, Tao W-K, Atlas R, Gu Y, Liou KN, Del Genio A, Khairoutdinov M, Gettelman A. 2005. Comparisons of EOS MLS cloud ice measurements with ECMWF analyses and GCM simulations: Initial results. Geophys. Res. Lett. 32: L18710, DOI: 10.1029/2005GL023788.

Lin B, Rossow WB. 1997. Precipitation water path and rainfall rate estimates for oceans using special sensor microwave imager and International Satellite Cloud Climatology Project data. J. Geophys. Res. 102: 9359-9374.

Lohmann U, Roeckner E. 1996. Design and performance of a new microphysics scheme developed for the ECHAM general circulation model. Clim. Dyn. 12: 557-572.

Lynch DK, Sassen K, Starr D, Stephens G. (eds) 2002. Cirrus. Oxford University Press: Oxford, UK.

McFarlane NA, Boer GJ, Blanchet JP, Lazare M. 1992. The Canadian Climate Centre second-generation general circulation model and its equilibrium climate. J. Climate 5: 1013-1044.

McFarquhar GM, Heymsfield AJ. 1997. Parameterization of tropical cirrus ice crystal size distribution and implications for radiative transfer: Results from CEPEX. J. Atmos. Sci. 54: 2187-2200.

Reinhardt T, Wacker U. 2004. Impact of ice particle habits on simulated clouds. Geophys. Res. Lett. 31: L21106, DOI: 1029/2004GL021134.

Roeckner E, Bäuml G, Bonaventura L, Brokopf R, Esch M, Giorgetta M, Hagemann S, Kirchner I, Kornblueh L, Manzini E, RhodinA, Schlese U, Schulzweida U, Tompkins A. 2003. 'The atmospheric general circulation model ECHAM5. Part I : Model description'. Report 349, Max-Planck-Institut: Hamburg.

Rydberg B, Eriksson P, Buehler SA. 2007. Prediction of cloud ice signatures in sub-mm emission spectra by means of ground-based radar and in situ microphysical data. Q. J. R. Meteorol. Soc. 133: $151-162$.

Rädel G, Stubenrauch CJ, Holz R, Mitchell DL. 2003. Retrieval of effective ice crystal size in the infrared: Sensitivity study and global measurements from TIROS-N Operational Vertical Sounder. J. Geophys. Res. 108: D9, DOI: 10.1029/2002JD002801.

Sreerekha TR, Emde C, Courcoux N, Teichmann C, Buehler SA, Loehnert U, Mech M, Crewell S, Battaglia A, Eriksson P, Rydberg B, Davis C, Jiménez C, English S, Doherty A. 2006. 'Development of an RT model for frequencies between 200 and $1000 \mathrm{GHz}$; Final report'. ESTEC Contract No 17632/03/NL/FF.

Stephens GL, Tsay S, Stackhouse PW Jr, Flatau PJ. 1990. The relevance of the microphysical and radiative properties of cirrus clouds to climate and climatic feedback. J. Atmos. Sci. 47: $1742-1753$.

Stephens GL, Vane DG, Boain RJ, Mace GG, Sassen K, Wang Z, Illingworth AJ, O'Connor EJ, Rossow WB, Durden SL, Miller SD, Austin RT, Benedetti A, Mitrescu C. 2002. The Cloudsat Mission and the A-Train. Bull. Am. Meteorol. Soc. 83: 1771-1790.

Stocker T. 2001. Physical climate processes and feedbacks. Chapter 7 in Climate Change 2001: The Scientific Basis. IPCC Third Assessment Report. Cambridge University Press: Cambridge, UK.

Stubenrauch C, Baran A, Brogniez G, Eddounia F, Edwards J, Macke A, Rädel G. 2004a. 'Cirrus microphysical properties and their effect on radiation: Survey and integration into climate models using combined satellite observations'. Final Report on the CIRAMOSA Environment project EVK2-CT-2000-00063, available at http://www.lmd.polytechnique.fr/CIRAMOSA/Welcome.html.

Stubenrauch CJ, Eddounia F, Rädel G. 2004b. Correlations between microphysical properties of large-scale semi-transparent cirrus and the state of the atmosphere. Atmos. Res. 72: 403-423.

Stubenrauch CJ, Eddounia F, Edwards JM, Macke A. 2007. Evaluation of cirrus parameterizations for radiative flux computations in climate models using TOVS-ScaRaB satellite observations. J. Climate in press.

Sun Z, Shine KP. 1994. Studies of the radiative properties on ice and mixed-phase clouds. Q. J. R. Meteorol. Soc. 120: 111-137.

Wilson D. 2000. The impact of a physically based microphysical scheme on the climate simulation of the Meteorological Office Unified Model. Q. J. R. Meteorol. Soc. 126: 1281-1300.

Winker DM, Pelon JR, McCormick MP. 2003. The CALIPSO mission: Spaceborn lidar for observation of aerosols and clouds. Proc. SPIE 4893: 1 -11. DOI: $10.1117 / 12.466539$.

Wu DL, Jiang JH, Davis CP. 2006. EOS MLS cloud ice measurements and cloudy-sky radiative transfer model. IEEE Trans. Geosci. Remote Sensing 44: 1156-1165.

Wylie DP, Menzel WP, Strabala KI. 1994. Four years of global cirrus cloud statistics using HIRS. J. Climate 7: 1972-1986. 